\title{
Volcanic plume characteristics determined using an infrared imaging camera
}

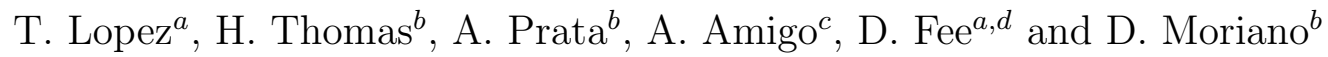 \\ ${ }^{a}$ University of Alaska Fairbanks Geophysical Institute and Alaska Volcano Observatory, \\ 903 Koyukuk Drive, Fairbanks, Alaska 99775 USA \\ ${ }^{b}$ Nicarnica Aviation, Gunar Randrs vei 24, Kjeller, N-2007, Norway \\ ${ }^{c}$ Volcano Hazards Program, Chilean Geological and Mining Service, SERNAGEOMIN, \\ Rudecindo Ortega 03850, Temuco, Chile, and \\ CEGA (Andean Geothermal Center of Excellence), Fondap 15090013, Chile \\ ${ }^{d}$ Wilson Infrasound Observatories, 903 Koyukuk Drive, Fairbanks, Alaska 99775, USA
}

\section{Abstract}

Measurements of volcanic emissions (ash and $\mathrm{SO}_{2}$ ) from small-sized eruptions at three geographically dispersed volcanoes are presented from a novel, multichannel, uncooled imaging infrared camera. Infrared instruments and cameras have been used previously at volcanoes to study lava bodies and to assess plume dynamics using high temperature sources. Here we use spectrally resolved narrowband ( $\sim 0.5-1 \mu \mathrm{m}$ bandwidth) imagery to retrieve $\mathrm{SO}_{2}$ and ash slant column densities $\left(\mathrm{g} \mathrm{m}^{-2}\right)$ and emission rates or fluxes from infrared thermal imagery at close to ambient atmospheric temperatures. The relatively fast sampling $(0.1-0.5 \mathrm{~Hz})$ of the multispectral imagery and the fast sampling $(\sim 1 \mathrm{~Hz})$ of single channel temperature data permit analysis of some aspects of plume dynamics. Estimations of $\mathrm{SO}_{2}$ and ash mass fluxes, and total slant column densities of $\mathrm{SO}_{2}$ and fine ash in individual small ex-

\footnotetext{
*Corresponding author: Taryn Lopez, phone: 1.907.978-4300, email: tlopez@gi.alaska.edu
}

Preprint submitted to Journal of Volcanology and Geothermal Research December 4, 2014

(C) 2014. This manuscript version is made available under the Elsevier user license http://www.elsevier.com/open-access/userlicense/1.0/ 
plosions from Stromboli (Italy) and Karymsky (Russia), and total $\mathrm{SO}_{2}$ slant column densities and fluxes from Láscar (Chile) volcanoes, are provided. We evaluate the temporal evolution of fine ash particle sizes in ash-rich explosions at Stromboli and Karymsky and use these observations to infer the presence of at least two distinct fine ash modes, with mean radii $<10 \mu \mathrm{m}$ and $>10$ $\mu \mathrm{m}$. The camera and techniques detailed here provide a tool to quickly and remotely estimate fluxes of fine ash and $\mathrm{SO}_{2}$ gas and characterize eruption size.

Keywords: Volcanic emissions, Volcanic plumes, Thermal imaging broadband

\section{Introduction}

2 Ground-based thermal infrared (IR) remote sensing has become a primary tool for volcano monitoring in recent years. High temporal resolu4 tion broadband thermal imaging cameras deployed in both ground-based and airborne configuration have been used at active volcanoes to monitor 6 changes in surface temperature (Carter et al., 2007; Wessels et al., 2013), es7 timate lava effusion rates (Harris et al., 2007), evaluate changes in lava lake s surfaces (Oppenheimer and Yirgu, 2002), image plume degassing (Ripepe eruptions (Ripepe et al., 2005a,b; Patrick et al., 2007; Marchetti et al., 2009; Lopez et al., 2013), constrain emission velocities and plume dynamics (Harris and Ripepe, 2007a; Patrick et al., 2007; Delle Donne and Ripepe, 2012), and quantify eruption and emission masses (Delle Donne and Ripepe, 2012; Harris et al., 2013). Additionally, multichannel thermal IR instruments, such as the 
airborne NASA Thermal Infrared Multispectral Scanner (TIMS) (Realmuto et al., 1994, 1997), and the nicAIR camera (Prata and Bernardo, 2009; Lopez et al., 2013), discussed here, exploit the characteristic IR absorption features of $\mathrm{SO}_{2}$ gas, ice, and silicate ash, to allow $\mathrm{SO}_{2}$ and very fine silicate ash to be detected and quantified. Here we describe methods for using nicAIR camera data to constrain ash and $\mathrm{SO}_{2}$ slant column densities (SCDs), quantify plume ascent speeds, determine $\mathrm{SO}_{2}$ and fine ash masses for individual explosions, and estimate mass fluxes of fine ash and $\mathrm{SO}_{2}$. We apply these techniques at three active volcanoes exhibiting various styles of degassing and explosive eruptive activity: Stromboli (Italy), Karymsky (Russia), and Láscar (Chile). We include brief descriptions of the nicAIR camera and the retrieval methods for detection and quantification of ash and $\mathrm{SO}_{2}$ and refer readers to Prata and Bernardo (2009) and Prata and Bernardo (2014) for further details.

The purpose here is not to provide new insights on volcanic processes, but rather to show the potential applications of the nicAIR camera to characterize volcanic plumes containing fine ash and/or $\mathrm{SO}_{2}$ gas. The restriction to fine ash retrievals is emphasized as the results presented do not include ash mass estimates for particles with radii greater than approximately $50 \mu \mathrm{m}$. Here we aim specifically to illustrate what can be determined from thermal imagery, to present some basic methods for processing these data, and to report on the limitations and difficulties associated with this type of measurement.

\section{The nicAIR Infrared imaging camera}

The nicAIR is a multispectral IR imaging camera designed for portable field deployment at volcanoes and in industrial settings (Prata and Bernardo, 
$2009,2014)$. The system is capable of detecting and quantifying $\mathrm{SO}_{2}$ gas and particulates at sample rates of $0.1-0.5 \mathrm{~Hz}$ (or up to $1 \mathrm{~Hz}$ for single channel thermal data). The camera measures thermal radiation emitted and absorbed by gases and particles in plumes and clouds, and by using specialized software, the image data can be transformed into SCDs of $\mathrm{SO}_{2}$ or ash (in $\mathrm{gm}^{-2}$, also referred to as ash mass loading in the literature). These SCDs can be used with feature tracking in the plumes to calculate $\mathrm{SO}_{2}$ and ash fluxes (in $\mathrm{kg} \mathrm{s}^{-1}$ ). The sensitivity of the camera detector array is usually assessed by the Noise Equivalent Temperature Difference (NEDT), in Kelvin. For the broadband channel the NEDT $\approx 50 \mathrm{mK}$, but for the filtered channels this increases to $100-500 \mathrm{mK}$ depending on the scene temperature and filter. Apart from NEDT limitations, the ability of the camera to provide quantitative estimates of $\mathrm{SO}_{2}$ or ash SCDs depends on pixel size, distance to target, the transparency of the atmosphere between the camera and the plume, plume optical depth, the presence of interfering species (e.g. gases that absorb or emit in the waveband of 8-12 $\mu \mathrm{m}$ ) and problems associated with non-synchronicity of the multispectral imagery due to movement of the filter wheel. The minimum errors have been assessed to be $\sim 20 \%$ for $\mathrm{SO}_{2}$ by Prata and Bernardo (2014), but a full assessment of the error for ash retrieval has not yet been made. It is likely that due to inaccurate knowledge of the refractive indices of the ash and of the size and shape distributions of the particles, in addition to the problems mentioned above, the retrieval error will be somewhat larger than that for $\mathrm{SO}_{2}$. The error associated with ash retrievals from satellites is typically 40-60\% (Wen and Rose, 1994), and this size of error can be expected from the ground-based thermal camera 
retrievals described here for translucent plumes.

In Section 3, the methods used to process the data and obtain retrievals of $\mathrm{SO}_{2} \mathrm{SCD}$ and fluxes are provided and their accuracies assessed. Ash retrievals are also presented for several cases and an estimate of the flux of fine ash particles $(r<50 \mu \mathrm{m})$ is made in the case of Stromboli. The system has a $24 \mathrm{hr}$ capability and can be deployed in an automated manner to provide volcano observatories with continuous information on $\mathrm{SO}_{2}$ and ash fluxes, and the maximum plume height of individual explosions. This last parameter may be useful as an input parameter to initialize dispersion models for forecasting the movement of volcanic ash clouds.

\subsection{Technical specifications and deployment scenarios}

Table 1 provides detailed technical specifications of the nicAIR camera system. An example of a typical camera deployment in which the camera is viewing $\mathrm{SO}_{2}$ degassing from Láscar volcano (see Section 4.3) is shown in Figure 1. In this example the camera is located $\sim 6.5 \mathrm{~km}$ from the degassing vent and tilted slightly upwards to view the plume and some clear sky. In addition to viewing and quantifying daytime emissions, the nicAIR has the significant advantage over ultraviolet (UV) instruments (Kern et al., 2014) of also being able to measure emissions at night. During the Stromboli Workshop (the main topic of this Special Issue), the nicAIR camera was set up to measure continuously and to view both ash and gas emissions during both day and nighttime conditions. Figure 2 shows a sequence of 20 broadband IR images, each separated by $\sim 20$ s that capture discrete explosions from Stromboli Volcano. These explosions could be easily detected and tracked for periods of several minutes using the camera during the day 
and/or night. Table 2 lists the locations and important deployment logistics of the nicAIR cameras at the three volcanoes studied.

\section{Quantifying $\mathrm{SO}_{2}$ and ash slant column densities and fluxes}

\section{1. $\mathrm{SO}_{2}$ retrievals}

$\mathrm{SO}_{2}$ gas has a strong IR absorption feature situated near $8.6 \mu \mathrm{m}$. This absorption band has been used by Realmuto et al. (1997) among others to determine the $\mathrm{SCD}$ of $\mathrm{SO}_{2}$ using multispectral data from airborne and spaceborne instruments. Prata and Bernardo (2014) have described the retrieval scheme for determining $\mathrm{SO}_{2}$ from the nicAIR imaging camera and we follow that procedure here. The retrieval procedure uses three channels at central wavelengths of 8.6, 10 and $12 \mu \mathrm{m}$ (or the broadband channel). The information regarding $\mathrm{SO}_{2}$ in the plume is contained in the $8.6 \mu \mathrm{m}$ channel, while the $12 \mu \mathrm{m}$ channel is used to correct for atmospheric effects, and the $10 \mu \mathrm{m}$ channel, which is the most transparent to water vapor absorption, is used to estimate the plume temperature. The retrieval scheme estimates the emissivity of the gas plume and determines the $\mathrm{SO}_{2} \mathrm{SCD}\left(\mathrm{g} \mathrm{m}^{-2}\right)$ from a laboratory measured absorption coefficient integrated over the filter response of the channel. The $\mathrm{SO}_{2} \mathrm{SCD} m_{s}$, is calculated using the following equation from Prata and Bernardo (2014):

$$
m_{s}=\rho d=-\frac{1}{k} \cos \theta \cos \phi \ln [1-\epsilon],
$$

where $\rho$ is the concentration, $d$ is path length through the plume, $k$ is the absorption coefficient averaged over the response function of the measurement 
channel, $\theta$ and $\phi$ are the camera viewing angles, and $\epsilon$ is an effective emissivity of the plume calculated using the method of Prata and Bernardo (2014). Note that $m_{s}$ and $\epsilon$ have the same dimensions as an image frame (e.g. 640 $\mathrm{x} 512$ pixels $\mathrm{x}$ lines) but only a subset of these contain $\mathrm{SO}_{2}$ after processing. Data are screened by differencing images to determine times when plumes are relatively ash-free (see Section 3.3), and only ash-free images are evaluated here for $\mathrm{SO}_{2} \mathrm{SCD}$. Note that at the time of writing no method exists to correct for the presence of ash while retrieving $\mathrm{SO}_{2}$; a scheme to simultaneously determine both $\mathrm{SO}_{2}$ and ash is currently under development.

\subsection{Ash retrievals}

A general retrieval scheme for ash SCD and particle size from multispectral IR camera measurements has been described by Prata and Bernardo (2009). The scheme is applicable in cases where the plumes are semi-transparent, usually at times 10-30 minutes after an ash explosion or at the edges of a rising plume, and is limited to fine-ash with radii $<16 \mu \mathrm{m}$. At the start of an eruption the ash plume is quite often opaque such that retrieving information on the particle size and ash SCD is not possible. For the cases of semi-transparent plumes we have developed a new method that uses three IR channels and an a priori model size distribution to estimate total ash mass for particles of radii $<50 \mu \mathrm{m}$, which extends the range of particle sizes detected using the method of Prata and Bernardo (2009) by a factor of three, but is still restricted to fine ash (as defined by Rose and Durant (2009)). It is well known that retrieving microphysical parameters from optical remote sensing data is an ill-posed problem (Liu et al., 1999). The general problem requires inversion of a Fredholm integral of the first kind and can be stated 
as:

$$
\tau(\lambda)=\int_{r_{\text {min }}}^{r_{\max }} K(r, \lambda ; \mathcal{R}) \frac{d n(r)}{d \ln r} d r,
$$

where $K(r, \lambda ; \mathcal{R})$ is a kernel which depends on the particle radius $r$, the wavelength $\lambda$, and implicitly on the complex index of refraction $(\mathcal{R})$ of the particles, through an extinction coefficient. The size distribution to be determined, $d n(r) / d \ln r$, appears inside the integral with limits $r_{\min }$ and $r_{\max }$ which are set by the spectral range of the measurements and the size range of particles under study.

The discrete version of (2) may be written:

$$
\Delta \mathbf{H}=\mathbf{K}^{-1} \Upsilon
$$

where $\Delta \mathbf{H}$ is the frequency distribution which can be related to the particle size distribution (PSD) from $\Delta \mathbf{H}=\Delta \mathbf{r H}$, where $\Delta \mathbf{r}$ is the particle size increment and $\mathbf{H}$ is the PSD. $\mathbf{K}$ is the kernel matrix and $\boldsymbol{\Upsilon}$ is a set of measurements of optical depth. The elements of $\mathbf{K}$ may be calculated using Mie theory using an assumed size distribution of spherical particles and an assumed complex index of refraction. Recognizing the difficulty of solving this inverse problem with just three or four spectral measurements, a scheme has been developed to simplify this problem. This scheme uses the spatial distribution of the measured optical depths within an ash plume to infer the PSD, based on an a priori model with two free parameters. This assumes that the extinction does not depend on particle size, but rather the number of particles in the atmospheric column, and tends to be a better approximation for larger particles $(r>16 \mu \mathrm{m})$. Further details of the scheme are provided 
in the Appendix.

\subsubsection{A priori size distribution model}

Volcanic ash PSDs have been frequently modeled using a log normal distribution (Wohletz, 1983; Bonadonna and Phillips, 2003; Rose and Durant, 2009) for very fine $(r<30 \mu \mathrm{m})$, fine $(30<r<63 \mu \mathrm{m})$ and coarse $(r>63 \mu \mathrm{m})$ particle sizes. Retrievals for larger particles $r>\sim 50 \mu \mathrm{m}$ and very small particles $r<1 \mu \mathrm{m}$ are not possible from the spectral measurements used here. The a priori log normal distribution model employed here is represented as,

$$
\frac{d n(r)}{d \ln r}=\frac{1}{\sigma_{l} \sqrt{2 \pi}}\left[\exp -\left\{\frac{(\ln r-\ln \mu)^{2}}{2 \sigma_{l}^{2}}\right\}\right]
$$

where $\mu$ and $\sigma_{l}=\ln (\sigma)$, are the first two moments of the distribution and are treated as free parameters to be estimated using a least squares minimization routine. It should be clear that the retrieval depends entirely on the choice of a priori size distribution and other choices for the underlying size distribution are possible.

\subsubsection{Optical depths}

The IR optical depth can be used along with the a priori model to estimate the PSD for $r<50 \mu \mathrm{m}$. The optical depth $\left(\tau_{\lambda}\right)$ can be estimated using the simple absorption model of Prata and Grant (2001). Assuming no scattering and considering monochromatic radiation with plane-parallel geometry, the IR emissivity at wavelength $\lambda$ may be written,

$$
\epsilon_{\lambda}=\frac{R_{p}-R_{\lambda}}{R_{p}-R_{b}}
$$




$$
R_{p}>R_{b},
$$

where $R_{b}$ is a background atmospheric radiance, $R_{p}$ is the plume radiance determined from an estimate of the plume temperature $\left(T_{p}\right)$, and $R_{\lambda}$ is the measured radiance at wavelength $\lambda$. The background radiance is determined from the broadband channel, but the plume radiance is more difficult to determine (see next subsection).

The optical depth is related to the plume emissivity by

$$
\tau_{\lambda}=-\ln \left[1-\epsilon_{\lambda}\right]
$$

Channels at 10 and $11 \mu \mathrm{m}$ are used to identify pixels in the images that have an ash signature. The condition for identifying a pixel containing 'ash' is,

$$
T_{\lambda_{1}}-T_{\lambda_{2}}<\Delta T_{0}
$$

where $T_{\lambda_{1}}$ and $T_{\lambda_{2}}$ are measured brightness temperatures (in this case at $\lambda_{1}=10 \mu \mathrm{m}$ and $\left.\lambda_{2}=11 \mu \mathrm{m}\right)$ and $\Delta T_{0}$ is a threshold temperature difference, taken as $\Delta T=0 \mathrm{~K}$. The basis for this ash detection technique is described in Prata and Bernardo (2009). A third channel (the broadband channel is suitable) is used to identify the plume and background temperatures needed to estimate the optical depth (Fig. 3), which is determined at $10 \mu \mathrm{m}$.

\subsubsection{Plume temperature}

There are several different ways to estimate plume radiance. One is to look for a very opaque part of the plume and use the broadband measurement to determine the plume temperature by assuming the plume is a blackbody. 
This temperature can then be re-inserted into the Planck function and the plume radiance at the wavelength, $\lambda$ can be determined. A second way is to assume that the plume is in thermal equilibrium with its surroundings, and use an estimate of the air temperature at the level of the plume as the plume temperature, and again invert the Planck function with this temperature. A third way is to look for parts of the plume where the radiance at two wavelengths agree within a specified amount (selected as $\sqrt{2}$ times the sum of the noise equivalent radiances for the channels); the assumption being that at these places the plume is behaving as a grey body with a high emissivity. These parts of the plume must also be opaque, such that the temperature contrast between the background sky and the plume is as high as possible. Having calculated the radiance by one of these methods, the radiance must then be corrected for atmospheric absorption (and possibly emission) for the path between the plume and the camera. Prata and Bernardo (2014) show that the size of this correction is typically $\pm 3 \mathrm{~K}$, and is dependent on the slant range distance between plume and camera. The optical depth error $\delta \tau_{\lambda}$ associated with an error in the estimated plume radiance $\delta R_{p}$ is:

$$
\delta \tau_{\lambda}=\frac{1}{\left(R_{p}-R_{b}\right)} \delta R_{p}
$$

The optical depth error is small when the contrast between the plume and background radiances is large (e.g. thick plume against a cold clear sky). For measurements at $10 \mu \mathrm{m}$, and considering a plume temperature of $280 \mathrm{~K}$ and a background sky temperature of $270 \mathrm{~K}$, the resulting optical depth error $\delta \tau_{10}$ would be $\sim \pm 0.2$ for a plume temperature error of $\pm 2 \mathrm{~K}$. This suggests that an error in optical depth estimation of at least $10 \%$ for optically thick clouds 
$(\tau \sim 2)$ will be due to plume temperature error alone. Figure 3 illustrates the plume temperature variation for a typical Strombolian 'ashy' eruption, where the ash cloud has detached from its source and is being advected by the local winds. A vertical transect through one part of the plume (solid line) is compared with a transect outside the plume (vertical dashed line). In this case the plume temperature is estimated as the maximum temperature along the transect $(\sim 290 \mathrm{~K})$ and the background temperature is estimated at the same height outside the plume $(\sim 272 \mathrm{~K})$, giving a temperature contrast of $\sim 18$ K. The shape of the temperature profile inside the plume is due to opacity changes with height together with an effect due to the atmospheric temperature lapse rate (decreasing temperature with altitude in the troposphere), which is clearly seen in the profile outside the plume. Horizontal variation of the plume temperature is assumed to be due only to opacity variations. In the image shown in Figure 3, the horizontal gradient varies by less than $1 \mathrm{~K}$ for the region of the sky above the plume and by less than $2 \mathrm{~K}$ for regions that include the plume.

\subsubsection{Size distribution retrieval}

The distribution of optical depths is used to estimate parameters of the PSD by assuming that the optical depths and PSDs are (1) equivalent and (2) scaled by a constant factor, the mean effective particle size, set by the assumed constant mass absorption coefficient (see Section 3.3.6). The mean effective particle size used here is $10 \mu \mathrm{m}$. The following steps are taken to condition the data to ensure stability of the retrieval. First, the images are shifted by a small amount (typically $1-5$ pixels) in pixel/line space to improve spatial coherence between images at different wavelengths acquired during 
the same duty cycle but at slightly different times. Because of the finite time required to move the filter wheel, images are never simultaneous and plumes typically move a small distance between successive images. Secondly, images are smoothed with a median filter with a filter length of 3 pixels and optical depths where $\tau<0.01$ and $\tau>5$ are not considered. This last condition places constraints on the smallest and largest particle sizes that can reliably be retrieved of $\sim 1 \mu \mathrm{m}$ and $\sim 50 \mu \mathrm{m}^{1}$, because we have assumed that the opacity is directly related to the particle size, and there are limits on the opacity determination. Once a retrieval of the optical depth has been performed, an elliptical region around the plume is identified and the histogram of optical depths within this ellipse is computed.

\subsubsection{Ash slant column densities}

The following equation shows the relationship between ash $\operatorname{SCD}\left(\mathrm{g} \mathrm{m}^{-2}\right)$ and optical depth, $\tau$ :

$$
m_{l}(i)=\frac{\tau(i)}{k_{a b s}}
$$

$$
k_{a b s}=\frac{3}{4} \frac{Q_{e x t}^{\infty}}{\rho}
$$

where $m_{l}(i)$ is the ash SCD for pixel number $i, k_{a b s}$ is a mass absorption coefficient $\left(\mathrm{m}^{2} \mathrm{~g}^{-1}\right), \rho$ is the density of the particle $\left(\mathrm{g} \mathrm{m}^{-2}\right)$, and $Q_{e x t}^{\infty}$ is the extinction efficiency $\left(\mathrm{m}^{-1}\right)$, which for large particle sizes may be treated as a constant, independent of the size distribution. Mie calculations for $r_{e}>16$ $\mu \mathrm{m}$, where $r_{e}$ is the effective radius, suggest $Q_{\text {ext }}^{\infty} \sim 0.048 \times 10^{6} \mathrm{~m}^{-1}$ at $10 \mu \mathrm{m}$

\footnotetext{
${ }^{1}$ These limits are not strict because the opacity retrieval depends also on the clarity of the intervening atmosphere for low opacity clouds and when the opacity is high, a small change in retrieved opacity gives a large change in the retrieved particle size.
} 
wavelength for andesitic, spherical ash particles (see Prata (1989), Figure $1)$.

Previous work (Prata, 1989; Wen and Rose, 1994; Francis et al., 2012) has shown that the ash composition has an important effect on the mass absorption, but the ash particle shape is less important. The effect of errors in the mass absorption coefficient due to errors in composition will be to scale the retrieved SCDs (and total mass) by some amount. The effect of assuming $k_{a b s}$ to be independent of particle size will be more complex. It is certainly not a justifiable assumption for smaller $(r<\sim 16 \mu \mathrm{m})$ particles, but we note that most of the mass resides in the larger particle size range.

\subsection{Plume rise-optical flow}

Measurements of plume rise do not require multispectral imagery such that the nicAIR camera can be operated in single-channel mode to increase the frequency of data acquisition up to $1 \mathrm{~Hz}^{2}$. Previous studies of plumes using imaging cameras have used feature tracking (Bluth et al., 2007) and edge detection (Lopez et al., 2013). The dynamic and often turbulent nature of volcanic plumes means that rise rates are highly variable over short time scales and spatially within the plume, such that the aforementioned methods will therefore miss some inhomogeneity in motion. Here we present the implementation of an optical flow model over the range of eruptive settings to demonstrate the additional information that can be gathered on plume dynamics from infrared camera imagery.

\footnotetext{
${ }^{2}$ It is possible to get single-channel full-frame uncalibrated imagery at $\sim 7 \mathrm{~Hz}$; however for this application calibrated data are needed.
} 
Optical flow is defined as the distribution of velocities from the motion of objects, edges or shapes due to relative motion between the observer and the targets (Gibson, 1950). Optical flow methodologies attempt to compute the motion between two image frames at times $t$ and $t+\Delta t$ and are based on the assumption that the brightness $(I)$ of the pixel at $(x, y)$ (for the 2-dimensional plus time case) at time $t$ is equal to the brightness of the pixel at $(x+\Delta x$, $y+\Delta y)$ and time $t+\Delta t$. Thus:

$$
I(x, y, t)=I(x+\Delta x, y+\Delta y, t+\Delta t)
$$

\section{0} equ 1 b

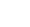
tica opti

\section{i}

20

of

300

301

A number of methodologies have been developed for solving the above equation and thus calculating optical flow. Six methods, developed prior to 1994 have been compared by Barron et al. (1994), although many more have been developed since (Liu et al., 1997; Jähne et al., 1998; Farneback, 2001).

The examples given here demonstrate an implementation of a dense optical flow algorithm following the method of Farnebäck (2003) where the optical flow is calculated for every pixel in the scene. The algorithm was implemented using the OpenCV library for Python (Bradski and Kaehler, 2008). The Farnebäck (2003) estimation utilizes the brightness assumption of Eq. (10) and estimates the motion of each pixel assuming that neighboring pixels undergo similar levels of displacement through the quadratic polynomial expression:

$$
F(I)=I \mathbf{A}^{T} I+b^{T} I+C,
$$

where $\mathbf{A}$ is a symmetric matrix, $b$ is a vector and $C$ is a scalar. The 
coefficients $b$ and $C$ are estimated from a weighted least squares fit to the signal values for all the pixels in the neighborhood. More weight is given to pixels close to the center of the neighborhood, and pixels outside of the image are ignored. The size of the pixel neighborhood to be considered is chosen by the user and can be made larger to improve robustness but will lose some of the intricacies of the motion (Farnebäck, 2003). Pyramid layers are used to increase the robustness of the algorithm when dealing with both small and large displacements. Each pyramid layer reduces the pixel resolution of the image by a specified factor, so that the number of pixels becomes fewer with each incremental layer.

A popular alternative method of solving the optical flow is that of Lucas et al. (1981) (the so-called Lucas-Kanade method). This method is a sparse technique, only calculating flow for significant features within the image. It was found in this application, however, that due to the local nature of the expansion method, it was less effective than the Farneback method in discriminating the flow patterns in the center of the clouds. Results for a discrete Strombolian eruption using the optical flow scheme are shown in Figure 4. An animation illustrating the complex plume dynamics during an explosive eruption of Karymsky Volcano using the optical flow model is shown in Supplementary Material 1.

\subsection{Mass fluxes (emission/transport rates) of $\mathrm{SO}_{2}$ and ash}

Since it is possible to retrieve the $\mathrm{SCD}$ of $\mathrm{SO}_{2}$ and ash, and estimate the two dimensional velocity field using optical flow, it is in principle possible to estimate the mass flux of $\mathrm{SO}_{2}$ and ash. The mass flux (in $\mathrm{kg} \mathrm{s}^{-1}$ ), is often referred to as the emission rate or transport rate in the literature, and may 
be defined as:

$$
\vec{J}=\rho \iint_{S} \vec{n} \cdot \vec{F} d S
$$

where $\vec{J}$ is the flux vector (or emission/transport rate), $\rho$ is the concentration of $\mathrm{SO}_{2}$ or ash, $d S$ is an elemental area of the plume surface $S, \vec{n}$ is a unit vector normal to $d S$ and pointing outwards from the surface, $\vec{F}$ is the velocity field vector and the integral is performed over a closed surface. The camera measurements only provide the SCD and the optical flow algorithm only provides two components of the velocity vector. Thus we can only estimate the component of the flux in directions defined in a plane with axes oriented orthogonal to the camera viewing direction. For simplicity if these axes are oriented so that the $x$-axis is parallel to the horizontal view angle and the $z$-axis is parallel to the vertical viewing direction then:

$$
\vec{F}=<\vec{u}, 0, \vec{w}>,
$$

where $\vec{u}$ and $\vec{w}$ are the velocity components in the $x$ and $z$ directions, respectively. In the following examples, the flux calculation is performed by dividing the plume surface into small elemental areas $(\delta A=\delta x \delta z)$, multiplying each element by both $|\vec{F}|$ and the SCD, and finally dividing by $\delta x$ (or $\delta z$, as these are chosen to be equal). The magnitude (scalar) flux of material, denoted by $|\bar{J}|$ (to distinguish it from the true vector flux, $\vec{J}$ ) from the volcano is then calculated as the average of all of these elemental fluxes. Note that we cannot estimate the true vector flux; only the components orthogonal to the camera view direction. With two cameras placed orthogonal to each other and in the same plane it is feasible to estimate $\vec{J}$. 


\section{Applications of nicAIR for volcanic plume characterization}

To illustrate the capabilities of the camera at determining volcanic plume characteristics, measurements from three different volcanoes are presented including Stromboli (Italy), Karymsky (Russia), and Láscar (Chile) (Figure 5). The nicAIR camera data are highly complementary to other geophysical datasets (e.g. infrasound data as in Lopez et al. (2013)) and theoretical models (e.g. for volcanic plume dynamics), and can be used in conjunction with these tools to obtain new insight into volcanic processes. These case studies were selected to illustrate different retrieval products. In the examples from Stromboli and Karymsky we explore the use of optical flow and ash mass retrievals to determine fluxes of fine ash. In the Láscar example we retrieve $\mathrm{SO}_{2} \mathrm{SCDs}$ and calculate fluxes. Each case presents different challenges: the Karymsky eruptions are much more explosive (and opaque) than those at Stromboli, where ash clouds rarely exceeded a few hundred meters from the vent and commonly drifted in the light winds. $\mathrm{SO}_{2}$ emissions at Láscar were much less energetic (low plume rise height) than those at Stromboli making the retrievals more difficult to perform. Maps showing the target volcanoes and the nicAIR location during each measurement period are shown in Figure 5.

\subsection{Stromboli}

\subsubsection{Volcano setting}

Stromboli Volcano $\left(38.789^{\circ} \mathrm{N}, 15.213^{\circ} \mathrm{E}, 924 \mathrm{~m}\right)$ is a potassium-rich basaltic to basaltic andesite volcano located in the Aeolian Archipelago of Italy (Rosi et al., 2000). Stromboli is famous for its persistent, low-level explosive activ- 
ity that has been occurring since $~ 700$ A.D. (Chouet et al., 1974; Barberi et al., 1993; Rosi et al., 2000). Typical activity at Stromboli consists of persistent degassing accompanied by discrete explosions occurring approximately every 5-20 minutes, which emit ash to block-sized scoracious material to heights ranging from tens to hundreds of meters above the vent (Barberi et al., 1993; Delle Donne et al., 2006; Lautze and Houghton, 2005; Patrick et al., 2007; Ripepe et al., 2008). This regular activity is punctuated by more energetic major explosions (Bertagnini et al., 1999), effusion of lava flows (Calvari et al., 2011), and less frequently, paroxysmal eruptions, which are higher energy explosions, producing ash clouds to $>10 \mathrm{~km}$ altitudes and erupting large volumes of ejecta (Barberi et al., 1993). Multiparameter observational datasets and model interpretations suggest that explosions at Stromboli are due to gas accumulation and ascent within the conduit, culminating in bubble burst at the magma free surface (Blackburn et al., 1976; Jaupart and Vergniolle, 1988; Harris and Ripepe, 2007a). Emissions of ash and gas from Stromboli are sourced from three primary vents within the summit crater terrace (Bertagnini et al., 1999). Previous estimates of total gas flux during periods of quiescent degassing have been determined using a combination of ground based remote sensing instruments including COSPEC and open-path FTIR, and direct sampling, and find a value of $5400 \pm 860 \mathrm{t}^{\text {day }^{-1}}$ $\left(62 \pm 10 \mathrm{~kg} \mathrm{~s}^{-1}\right)$, which includes $250 \pm 50 \mathrm{t}_{\text {day }}{ }^{-1}\left(3.0 \pm 0.5 \mathrm{~kg} \mathrm{~s}^{-1}\right) \mathrm{SO}_{2}$ (Allard et al., 2008). Note that gas fluxes during eruptive periods will be greater, for example Burton et al. (2009) found an average daily $\mathrm{SO}_{2}$ flux of $620 \mathrm{t}$ day $^{-1}\left(7.2 \mathrm{~kg} \mathrm{~s}^{-1}\right)$ during the 2007 eruption using the continuous FLAME network of UV spectrometers; however previous work suggests that quies- 
cent degassing represents $95 \%$ of total $\mathrm{SO}_{2}$ degassing at Stromboli (Allard et al., 1994). The combined mass of lava, ash and gas emitted from individual Strombolian explosions has been estimated using visible or thermal image data in a number of studies, including Chouet et al. (1974), Ripepe et al. (1993), Harris and Ripepe (2007a), Delle Donne and Ripepe (2012) and Harris et al. (2013). The most recent of these studies estimate the mass of bombs and gas/ash emitted during individual explosions using thermal remote sensing imagery of the bomb field and ascending plume (Harris et al., 2013) and find minimum bomb and gas/ash masses ranging from 900$31400 \mathrm{~kg}$ (mean value of $9113 \pm 11466 \mathrm{~kg}$ ), and 109-1054 kg (mean value of $623 \pm 340 \mathrm{~kg})$, respectively. These results are in good agreement with Ripepe et al. (1993), but significantly higher than the other studies (mean value $\sim 7-$ 200 times larger than the minimum values found) (Harris et al., 2013). These estimates use volumes of emitted material (calculated from plume or bomb area within the image) to calculate bomb and gas/ash masses, which depend on significant assumptions regarding the plume composition and density, unlike data from the multichannel camera employed here, which can distinguish fine ash and gas. Additionally, a study by Mori and Burton (2009) find a total mass of $\mathrm{SO}_{2}$ released during individual Strombolian explosions to range from 15-40 kg using a UV camera.

\subsubsection{Experimental setup}

For several days in June 2013 the nicAIR camera was used to measure $\mathrm{SO}_{2}$ and ash within plumes associated with explosions from Stromboli. The nicAIR camera was set up approximately $2.6 \mathrm{~km}$ from the two main erupting vents at an inclination angle of $\sim 14$ degrees above the horizontal. With this 
geometry the average pixel size is $\sim 7 \mathrm{~m}^{2}$ (Table 2).

\subsubsection{Ash results}

Ash retrievals were performed over several periods for which isolated small, ash-rich explosions occurred, described by Patrick et al. (2007) as Type 2 Strombolian eruptions. These "puffs" seldom rose to more than a few hundred meters above the vent and dissipated within 5-10 minutes. The plumes were clearly buoyant and were dispersed by light winds. Results of fine ash mass and PSD are presented for 23 June when winds were light $(<5$ $\mathrm{m} \mathrm{s}^{-1}$ ) and the weather conditions were favorable with only a few meteorological clouds. Figure 6 shows a period from 18:05 UT through to 18:09 UT, when a small ash puff could be tracked as it moved southwestwards from the vent towards the coast. The total mass of fine ash in these ash-rich puffs is estimated to be up to $\sim 2000 \mathrm{~kg}(\sim 2 \mathrm{t})$, with a bimodal size distribution and median peaks in effective particle radii near to $\sim 20-30 \mu \mathrm{m}$ and $\sim 0.5-10 \mu \mathrm{m}$ (Figure 6 and 7). Within five minutes of emission the mass dropped to $\sim 500$ $\mathrm{kg}(\sim 0.5 \mathrm{t})$ and most of the remaining ash particles had radii $<10 \mu \mathrm{m}$, with a median peak of $\sim 0.5 \mu \mathrm{m}$ (Figure 6 ). At the end of the sequence of retrievals, when the puff had all but dissipated, the ratio of pixels with radii less than 10 $\mu \mathrm{m}$ to those with radii greater than $10 \mu \mathrm{m}$ is $\sim 6 \%$. One interesting finding of the IR retrievals is that there appears to be an airborne fraction remaining in the atmosphere with median particle radius $\sim 0.5 \mu \mathrm{m}$, or perhaps smaller (Figure 6). The majority of the larger particles (aerodynamic radii $>100 \mu \mathrm{m}$ ) have fallen to the ground within 30 minutes of the explosion onset, consistent with the timescale for gravitational settling speeds of $\sim 0.3 \mathrm{~m} \mathrm{~s}^{-1}$. The evolution of the median radius for the two modes is shown in Figure 7, together 
with the total mass of fine ash. The temporal behavior of the PSDs shows no evidence of particle aggregation in the cases studied, since at all later times the size distribution shifts to smaller particles, eventually reaching sizes too small to be resolved by the IR camera.

The mass flux of fine ash within discrete explosions can be estimated using a combination of the ash mass retrievals and the plume velocity determined from the optical flow methodology as described in Section 3.3. Figure 8 illustrates an example from 18:24 UT to 18:28 UT on 23 June 2013, where the nicAIR camera observed an ash cloud produced by a discrete explosion that emerged from the vent into the atmosphere. Reliable fine ash mass estimates and plume velocities are obtained within $\sim 30 \mathrm{~s}$ of the first observation, and up to $\sim 5$ minutes afterwards. Before $\sim 30 \mathrm{~s}$ and beyond $\sim 5$ minutes, the IR optical depth is too high and too low, respectively, for reliable estimates to be made. In this case the optical flow model output has been resampled to a grid of one vector every 6 pixels which returns velocity values at $\sim 20 \mathrm{~m}$ intervals. The mean and standard deviation of the fine ash flux over the eruption cloud is calculated and plotted for each image in the sequence lasting $\sim 5$ minutes (Figure 9). A total fine ash mass emitted of $\sim 4000 \mathrm{~kg}$ (4 t), a mean fine ash mass flux of $\sim 53 \pm 26 \mathrm{~kg} \mathrm{~s}^{-1}$, and a maximum fine ash mass flux (determined from the peak of the Gaussian) of $\sim 84 \mathrm{~kg} \mathrm{~s}^{-1}$ are found. Other discrete explosions observed during the field campaign and analyzed in this way gave similar results as those shown in Figure 9. An animation depicting the ash mass flux results for a four minute period corresponding with the Stromboli explosion shown in Figures 8 and 9 can be seen in Supplementary Material 2 . 


\section{2. $\mathrm{SO}_{2}$ results}

During the period of measurements at Stromboli, the volcano was degassing $\mathrm{SO}_{2}$ nearly continuously. $\mathrm{SO}_{2}$ retrievals were made for sequences of measurements lasting 1-3 hours during the day and night. Figure 10 illustrates the nicAIR $\mathrm{SO}_{2}$ retrieval that can be directly compared with the results presented in Kern et al. (2014) which includes results for the same plume from six different $\mathrm{UV} \mathrm{SO}_{2}$ camera systems. The range of values found for this particular explosion, by Kern et al. (2014) was 127-209 kg, compared with $161 \mathrm{~kg}$ determined from the nicAIR (IR) measurements. The range in average $\mathrm{SO}_{2}$ masses emitted for four explosions analyzed by Kern et al. (2014) on this day was 51-160 kg, compared to results from Mori and Burton (2009), who used similar techniques in 2006 and found $15-40 \mathrm{~kg} \mathrm{SO}$ per explosion. Lopez et al. (2013) also did some comparisons between the nicAIR camera and a UV spectrometer system at Karymsky Volcano and found good agreement in $\mathrm{SO}_{2} \mathrm{SCD}$. Many more comparisons are required before definitive assessments can be made concerning the accuracy of the IR $\mathrm{SO}_{2}$ retrieval, but the experience at several different volcanoes suggests that the IR sensor is less sensitive to $\mathrm{SO}_{2}$ (i.e. has a lower signal to noise ratio) in comparison with the UV camera sensors.

\subsection{Karymsky}

\subsubsection{Volcano setting}

Karymsky Volcano $\left(54.05^{\circ} \mathrm{N}, 159.45^{\circ} \mathrm{E}, 1536 \mathrm{~m}\right)$ is a predominantly andesitic stratovolcano located in the Eastern Volcanic Front of Russia's Kamchatka Peninsula. Since its current eruptive cycle began on 2 January 1996 it has been in a nearly continuous state of unrest, with activity consisting 
of discrete explosive eruptions of ash and gas reaching altitudes up to $6 \mathrm{~km}$, periodic effusion of lava flows and/or extrusion of summit domes, and various styles of frequently-audible degassing (e.g. jetting, chugging, etc.) (Johnson et al., 1998; Johnson and Lees, 2000; Fischer et al., 2002; Izbekov et al., 2004; Lopez et al., 2013). The various styles of activity exhibited at Karymsky Volcano have been attributed to changes in conduit permeability and magma recharge from depth (e.g . Fischer et al. (2002); Ozerov et al. (2003); Johnson (2007); Lopez et al. (2013)). The frequent explosions and variable styles of activity exhibited at Karymsky Volcano have made it a laboratory-type volcano that has supported numerous multiparameter investigations (e.g. (Johnson et al., 1998; Johnson and Lees, 2000; Fischer et al., 2002; Lopez et al., 2013). Measurements of $\mathrm{SO}_{2}$ fluxes from Karymsky volcano were first made by Fischer et al. (2002) in 1999 using a COSPEC (Correlation Spectrometer) (Stoiber et al., 1983). They observed highly variable $\mathrm{SO}_{2}$ fluxes, corresponding with cycles of eruptive activity, with values ranging from near detection limit to $1.63 \mathrm{~kg} \mathrm{~s}^{-1}$. Similarly, Lopez et al. (2013) found variable $\mathrm{SO}_{2}$ fluxes in 2011 and 2012 ranging from $<0.14 \mathrm{~kg} \mathrm{~s}^{-1}$ to $3.2 \mathrm{~kg} \mathrm{~s}^{-1}$ using a FLYSPEC UV spectrometer (Horton et al., 2006) and the nicAIR camera. Lopez et al. (2013) estimated a total eruptive mass of very fine ash $(r<16 \mu \mathrm{m})$ for a relatively large explosive eruption at Karymsky observed on August 22, 2011 of $>69000 \mathrm{~kg}$ using the nicAIR camera.

\subsubsection{Experimental setup}

Between 13-24 August 2011 the nicAIR camera was deployed $\sim 3.58 \mathrm{~km}$ southeast of the summit vent (Figure 5). During this study period measurements of Karymsky's volcanic emissions were collected. The instrument 
viewed activity at a slant distance of $3690 \mathrm{~m}$ with a $\sim 15^{\circ}$ inclination angle. This viewing geometry resulted in an average pixel size of $\sim 12 \mathrm{~m}^{2}$ (Table 2). Volcanic activity was characterized as highly variable, and included gas jetting; pulsatory degassing; discrete ash explosions, producing ash clouds to 500-1500 m above the vent; and explosive eruptions that frequently followed periods of apparent vent sealing and produced ash clouds to $>2000 \mathrm{~m}$ above vent altitudes (Lopez et al., 2013). During this time period, background skies were typically cloud-free and the gas-only plume was primarily translucent. Occasionally, high winds blew the plume down the flank of the volcano towards the camera preventing accurate constraints on $\mathrm{SO}_{2}$ and ash SCDs and derived fluxes. These non-ideal time periods were excluded from analyses.

\subsubsection{Ash results}

Retrievals of ash SCD and effective particle size were performed for a series of images when Karymsky was exhibiting ash-rich explosions that were relatively vigorous and in many cases produced optically thick plumes. In these cases the particle size retrievals presented here are more reliable than the method described by Prata and Bernardo (2009). Ash eruptions from Karymsky generally gave total fine-ash mass retrievals above 10,000 kg (10 t). Figure 11 shows a sequence of ash retrievals at $\sim 20-30 \mathrm{~s}$ intervals for an ash-rich explosive eruption. The total masses retrieved (minimums) are $10000,24000,32000$ and $53000 \mathrm{~kg}$, respectively with increasing time from the start. This final value is not very different from that reported by Lopez et al. (2013) of $\sim 69000 \mathrm{~kg}$. These values are likely to be conservative minimum estimates of the fine ash mass, due to optical depth saturation for thick plumes preventing ash absorption from being accurately constrained. An 
example of this optical depth saturation can be seen in the panels of Figure 11 at the top half of the growing plume, where the combination of greater path length and particle numbers leads to high optical depths, and underestimated ash-mass retrievals. Figure 12 shows an example of a smaller eruption, in which case the IR image was acquired sometime after the initial explosion, where the optical depth is lower over almost the entire column of ash, such that more accurate ash mass retrievals are possible. The fine ash mass for this smaller eruption is estimated to be $\sim 10000-20000 \mathrm{~kg}$. For both of these examples the optical flow method was used to determine plume velocities, allowing an estimated minimum fine ash mass flux of $\sim 150 \mathrm{~kg} \mathrm{~s}^{-1}$ to be calculated for the large explosion (Figure 11). Figure 13 shows the plume velocity vectors calculated for the large eruption sequence and an animation of this sequence is found in Supplementary Material 1. Figure 14 shows the fine ash mass flux retrieval for the last image in the sequence, for which the highest flux was found.

\subsection{Láscar}

\subsubsection{Volcano setting}

Láscar Volcano $\left(23.37^{\circ} \mathrm{S}, 67.73^{\circ} \mathrm{W}, 5592 \mathrm{~m}\right)$ is an andesitic stratovolcano located in the Andean Central Volcanic Zone of Northern Chile, and is considered the most active volcano in this region (Matthews et al., 1997; Tassi et al., 2009). Between 1984 and 1996 Láscar underwent a period of cyclic lava dome growth and subsidence, persistent degassing, and explosive eruptions (Matthews et al., 1997). This eruptive period included a sub-Plinian eruption from 19-20 April of 1993 that produced an ash cloud up to $25 \mathrm{~km}$ altitude and produced over $0.1 \mathrm{~km}^{3}$ of eruptive material (Matthews et al., 
1997). Explosive activity during this eruptive cycle was attributed to changes in lava dome permeability, which led to dome pressurization and culminated in pressure release during explosion (Matthews et al., 1997). Activity since 1993 has been dominated by persistent degassing and periodic small ash explosions with associated ash clouds to altitudes less than $10 \mathrm{~km}$ Tassi et al. (2009).

\subsubsection{Experimental Setup}

Measurements of $\mathrm{SO}_{2}$ emissions were made using the nicAIR camera on 29-30 November 2012. During this time period volcanic activity was limited to persistent $\mathrm{SO}_{2}$ degassing. The nicAIR camera was deployed between 6.5 and $6.7 \mathrm{~km}$ northwest of the actively degassing crater, giving a pixel size of $\sim 40 \mathrm{~m}^{2}$ (Table 2).

\subsection{3. $\mathrm{SO}_{2}$ results}

The $\mathrm{SO}_{2}$ plume from Láscar was visible on both days of measurements in November 2011, but generally remained close to the volcano with very little lofting. The plume was clearly seen in visible light, appearing white in color, presumably due to condensed water in the plume. Figure 1 illustrates the typical plume character during the measurement period. Figure 15 shows an $8.6 \mu \mathrm{m}$ channel image (top) and the associated $\mathrm{SO}_{2}$ retrieval. The small plume and minimum temperature difference between the cold background sky ( $\sim 240-250 \mathrm{~K})$ and the plume ( $258 \mathrm{~K}$, estimated from the broadband channel), resulted in low signal to noise, which made the retrieval difficult, and increased the error. The calibration of the camera was initially found to give temperatures biased 10-15 K too low. An improved calibration proce- 
dure which takes into account the effect of self-radiation from the detector was subsequently introduced which increased the derived temperatures, but we suspect they may still be biased low by $1-3 \mathrm{~K}$. Self-radiation is an important contribution when the focal plane array (FPA) temperature used when calibrating the camera in the laboratory is very different from the temperature of the scene viewed by the camera in the field. In this case plume temperatures are $\sim 255-260 \mathrm{~K}$, while the FPA temperature was $\sim 290 \mathrm{~K}$, so that the FPA contribution was significant and unaccounted for in the original calibration. To improve the detection capabilities, the retrieval was focused on a rectangular region immediately above the vent where the plume signal was the strongest. The plume temperature was estimated at the base of the plume in a region of $3 \times 3$ pixels, just above the vent and no correction was made for the temperature lapse rate. Wind speeds were estimated using the optical flow method described in Section 3.7. The mean flux for this hour is close to $1.5 \pm 0.7 \mathrm{~kg} \mathrm{~s}^{-1}\left(\sim 130 \mathrm{t}^{\mathrm{day}}{ }^{-1}\right)$, but the variability is high $(\sim 50 \%$ of the signal) as can be seen in Figure 16. We estimate that approximately half of the variability may be attributed to retrieval error, poor calibration and errors in estimating the wind speed and plume temperature. Mather et al. (2004) found fluxes of $28 \mathrm{~kg} \mathrm{~s}^{-1}$ in January 2003, which are much higher than the values found here. Henney et al. (2012) reported $\mathrm{SO}_{2}$ gas measurements for 7 December, 2004 from a mini-UV spectrometer and estimated fluxes of 1.9-2.4 $\mathrm{kg} \mathrm{s}^{-1}$, similar to the mean values we find. 


\section{Conclusions}

Ground-based thermal infrared imaging of volcanic plumes at relatively cool temperatures, close to ambient atmospheric values, is a new technique that offers the potential to infer fine ash and $\mathrm{SO}_{2} \mathrm{SCD}$ and masses at high temporal resolution. When fine ash mass retrievals are combined with an a priori particle size distribution model, total ash mass for the size fraction $r<50 \mu \mathrm{m}$ can be calculated. This provides a potentially significant tool to quickly and remotely estimate plume fine ash fluxes and characterize eruption size, with important implications for volcano monitoring and hazard mitigation. We note that ash mass retrievals for opaque plumes will represent minimum estimates and error in the resulting PSD will likely be high. An optical flow algorithm was used to determine plume velocities and a scheme was proposed to combine ash and $\mathrm{SO}_{2} \mathrm{SCDs}$ with plume velocities to infer ash and $\mathrm{SO}_{2}$ fluxes, using a single consistent dataset. The ability to determine these parameters continuously over 24 hours also make the camera useful as a monitoring tool and for alerting communities about changes in volcanic activity. Examples of retrievals at Stromboli (Italy), Karymsky (Russia) and Láscar (Chile) volcanoes demonstrate the versatility of the system; since the instrument has the same capability during the night as the day, the measurements add value and complement those from other volcanological tools (e.g. the UV $\mathrm{SO}_{2}$ camera). The fine ash mass fluxes retrieved from the camera are in the same range of values determined from other studies using different instruments and methodologies. Future work will involve a robust validation of total ash and $\mathrm{SO}_{2}$ masses and fluxes, and a scheme will be developed to simultaneously quantify both ash and $\mathrm{SO}_{2}$, significantly improving 
the utility of these measurements. Preliminary results suggest errors in fine ash SCDs in the range of 20-50\% for semi-transparent plumes (with larger unconstrained error for opaque plumes), and errors of $\sim 20 \%$ for $\mathrm{SO}_{2} \mathrm{SCDs}$, with most of this error due to the fine ash mass and gas retrievals rather than wind velocity errors-usually a significant source of error in determining fluxes from independent wind data. The parameters determined by the camera are ideally suited for use in conjunction with other data to diagnose volcanic activity. In particular, the maximum height of the volcanic column, and fluxes of fine ash and $\mathrm{SO}_{2}$ gas found from the nicAIR imagery may be used to initialize dispersion models for forecasting atmospheric transport of volcanic ash and gas.

\section{Acknowledgement}

We thank the reviewers for their helpful comments and in particular we are most grateful to one anonymous reviewer for the thoroughness of the review which significantly improved this manuscript. Part of this work is funded by the European Commission FP7 project No 308377 (FUTUREVOLC). The CONICYT/FONDAP/15090013 project is thanked for also funding part of this work. Topographic data from the NASA ASTER instrument were used in Figure 5. TML acknowledges funding from the Geophysical Institute, the Alaska Space Grant Consortium, and NSF grant EAR 1250148. 
664

\section{Appendix: Optical depth retrieval}

The monochromatic optical path between two points, $\mathbf{s}_{\mathbf{1}}$ and $\mathbf{s}_{\mathbf{2}}$ in a cloud of particles may be written,

$$
\tau_{\lambda}\left(s_{1}, s_{2}\right)=\int_{s_{1}}^{s_{2}} \beta_{e x t}(\lambda, s) d s
$$

where $\beta_{\text {ext }}$ is an extinction coefficient with dimensions $\mathrm{m}^{-1}$ at wavelength $\lambda$. It is often more useful to consider the mass extinction along the path and reformulate (A-1) as,

$$
\tau_{\lambda}\left(s_{1}, s_{2}, r\right)=\int_{s_{1}}^{s_{2}} \int_{0}^{\infty} \pi r^{2} Q_{e x t}(\lambda, r) \frac{d N}{d r}(r) d r d s
$$

where now the dimensionless extinction efficiency factor $Q_{\text {ext }}(\lambda, r)$ replaces $\beta_{\text {ext }}(\lambda, r)$. The mass extinction is an integral over the size distribution $\frac{d N}{d r}$ where $\mathrm{N}$ is the number of particles per unit volume and the particle radius is $r$. It is now assumed that the size distribution and mass extinction are independent of position (s):

$$
\tau_{\lambda}=L \int_{0}^{\infty} \pi r^{2} Q_{e x t}(\lambda, r) \frac{d N}{d r}(r) d r,
$$

65 where $L=\left|\mathbf{S}_{\mathbf{1}}-\mathbf{S}_{\mathbf{2}}\right|$. It is commonly found in studies of volcanic plumes that the particle sizes follow a log-normal distribution :

$$
\frac{d N}{d r}=\frac{1}{r} \frac{N_{o}}{\sqrt{2 \pi} \ln \sigma} \exp \left\{-\left(\frac{\ln r-\ln \mu}{\ln \sigma}\right)^{2}\right\}
$$


where $\mu$ and $\sigma$ are the geometric mean and standard deviation of the distribution. The factor $1 / \sqrt{2 \pi}$ ensures that the integral of the distribution from $r=0$ to $r=\infty$ equals $N_{o}$, the total number of particles per unit volume. Equation (A-2) shows that, in principle, from a set of measurements of optical depths it is possible to infer the particle size distribution. The measurements may be spectral, for example from an FT-IR device, or they may be at one wavelength but at different angles, for example in a device that is able to perform zenith scans. In our case, the measurements consist of a large number $\left(0.01-0.1 \times 10^{6}\right)$ of image pixels, each measuring a different part of the same ash plume.

Let us now consider a monochromatic $(\lambda)$ thermal image of $M(l$ lines x $p$ pixels) measurements of a cloud of ash for which the size distribution is log-normal with $\mu=\mu_{k}$ and $\sigma=\sigma_{k}$. If the optical depth image is defined as $\tau_{\lambda}\left(L_{i}\right)$ then in matrix notation:

$$
\Upsilon=\mathbf{K H}^{T}
$$

and

$$
\mathbf{\Upsilon}=\left(\begin{array}{c}
\tau_{i} \\
\tau_{i+1} \\
\vdots \\
\tau_{M}
\end{array}\right)
$$

is a vector of measurements. $\mathbf{H}$ is a vector representing the size distribution, with each element given by:

$$
H_{j}=h_{j} d r
$$


where $d r$ is the particle size increment and $j=1 \cdots J$. The kernel $\mathbf{K}$ is a matrix with elements

$$
\mathbf{K}=\left(\begin{array}{ccccc}
q_{1,1} & q_{1,2} & q_{1,3} & \cdots & q_{1, J} \\
q_{2,1} & q_{2,2} & q_{2,3} & \cdots & q_{2, J} \\
\vdots & \vdots & \vdots & \vdots & \\
q_{M, 1} & q_{M, 2} & q_{1,3} & \cdots & q_{M, J}
\end{array}\right)
$$

where each element may be interpreted as an extinction factor for a particular pixel and particle size. Figure 17 shows the variation of the kernels with particle size for different wavelengths and Figure 18 shows the variation of the integrand as a function of particle size for several different values of $\mu_{k}$ with $\sigma=1.5$. These functions have been determined using a Mie scattering calculation for spherical andesitic particles and log-normal size distributions. The natural way to solve (A-5) is simply to write:

$$
\mathbf{H}=\mathbf{K}^{-1} \Upsilon
$$

however this is known to be an ill-posed problem and it is clear that the columns of $\mathbf{K}$ may be linearly dependent. As an illustration suppose the kernel function is chosen to be a constant, $q_{0}$ independent of particle size. Then the integral in (A-3) can be evaluated immediately to give:

$$
\tau_{i}=L_{i} \pi q_{o} N_{o} \exp \left\{2\left(\ln \mu+\ln ^{2} \sigma\right)\right\}
$$

Given $q_{o}$ and assuming that $L_{i}$ are known independently, then parameters of 
the (assumed) size distribution are uniquely determined. Unfortunately each of the $L_{i}$ are linearly dependent, leading to multiple solutions. The retrieval scheme chosen here relies on the correspondence between the distribution of particle sizes and the distribution of optical depths as shown in (A-2). Rather than attempting to retrieve particle sizes directly by inverting $\mathbf{K}$, through determining its elements using Mie scattering, the underlying form of the PSD is determined by fitting log-normals to the optical depth distribution. In this scheme there is a scaling between the particle size parameters ( $\mu$ and $\sigma$ ) proportional to $\mathbf{K}^{-1}$. This scaling is a constant factor in the current scheme and is chosen based on the premise that the particle sizes are likely to be large, viz. $r>16 \mu \mathrm{m}$. Prata (1989) showed that the extinction efficiency for large particles tends towards a constant value, while more recently Francis et al. (2012) show that for several different ash compositions and for three wavelengths (viz., 10.8, 12.0 and $13.4 \mu \mathrm{m}$ ) the scaled mass extinction coefficient tends towards a value of $\sim 0.02 \mathrm{~m}^{2} \mathrm{~g}^{-1}$. Figure 17 also shows that for particle sizes greater than $\sim 30 \mu \mathrm{m}, Q_{e x t} \rightarrow 2.0$, a constant. The assumption of an underlying log-normal size distribution can be changed to assume that the distribution is the linear sum of several log-normals, or indeed any PSD. The choice can be informed by examining the distribution of the measured optical depths, as has been done here.

\section{References}

Allard, P., Aiuppa, A., Burton, M., Caltabiano, T., Federico, C., Salerno, G., La Spina, A., 2008. Crater gas emissions and the magma feeding system 
of Stromboli volcano. The Stromboli Volcano: An Integrated Study of the 2002-2003 Eruption, 65-80.

Allard, P., Carbonnelle, J., Metrich, N., Loyer, H., Zettwoog, P., 1994. Sulphur output and magma degassing budget of Stromboli volcano. Nature 368 (6469), 326-330.

Barberi, F., Rosi, M., Sodi, A., 1993. Volcanic hazard assessment at Stromboli based on review of historical data. Acta Vulcanologica 3, 173-187.

Barron, J. L., Fleet, D. J., Beauchemin, S. S., 1994. Performance of optical flow techniques. International Journal of Computer Vision 12 (1), 43-77.

Bertagnini, A., Coltelli, M., Landi, P., Pompilio, M., Rosi, M., 1999. Violent explosions yield new insights into dynamics of Stromboli volcano. Eos, Transactions American Geophysical Union 80 (52), 633-636.

Blackburn, E., Wilson, L., Sparks, R., 1976. Mechanisms and dynamics of Strombolian activity. Journal of the Geological Society 132 (4), 429-440.

Bluth, G., Shannon, J., Watson, I., Prata, A., Realmuto, V., 2007. Development of an ultra-violet digital camera for volcanic $\mathrm{SO}_{2}$ imaging. Journal of Volcanology and Geothermal Research 161 (1), 47-56.

Bonadonna, C., Phillips, J., 2003. Sedimentation from strong volcanic plumes. Journal of Geophysical Research 108 (B7), 2340.

Bradski, G., Kaehler, A., 2008. Learning OpenCV: Computer vision with the OpenCV library. O’Reilly Media, Inc. 
Burton, M., Caltabiano, T., Murè, F., Salerno, G., Randazzo, D., 2009. $\mathrm{So}_{2}$ flux from stromboli during the 2007 eruption: Results from the flame network and traverse measurements. Journal of Volcanology and Geothermal Research 182 (3), 214-220.

Calvari, S., Spampinato, L., Bonaccorso, A., Oppenheimer, C., Rivalta, E., Boschi, E., 2011. Lava effusion - A slow fuse for paroxysms at Stromboli volcano? Earth and Planetary Science Letters 301 (1), 317-323.

Carter, A. J., Ramsey, M. S., Belousov, A. B., 2007. Detection of a new summit crater on Bezymianny Volcano lava dome: satellite and field-based thermal data. Bulletin of Volcanology 69 (7), 811-815.

Chouet, B., Hamisevicz, N., McGetchin, T. R., 1974. Photoballistics of volcanic jet activity at Stromboli, Italy. Journal of Geophysical Research 79 (32), 4961-4976.

Delle Donne, D., Lacanna, G., Marchetti, E., Ripepe, M., Ulivieri, G., 2006. Monitoring explosive volcanic activity using thermal images, Stromboli volcano, Italy. In: American Geophysical Union Fall Meeting Abstracts. Vol. 1. p. 1795.

Delle Donne, D., Ripepe, M., 2012. High-frame rate thermal imagery of Strombolian explosions: Implications for explosive and infrasonic source dynamics. Journal of Geophysical Research: Solid Earth 117 (B9).

Farneback, G., 2001. Very high accuracy velocity estimation using orientation tensors, parametric motion, and simultaneous segmentation of the motion field. In: Computer Vision, 2001. International Conference on Computer 
Vision 2001. Proceedings. Eighth Institute of Electrical and Electronic Engineers International Conference. Vol. 1. IEEE, pp. 171-177.

Farnebäck, G., 2003. Two-frame motion estimation based on polynomial expansion. In: Image Analysis. Springer, pp. 363-370.

Fischer, T. P., Roggensack, K., Kyle, P. R., 2002. Open and almost shut case for explosive eruptions: vent processes determined by $\mathrm{SO}_{2}$ emission rates at Karymsky volcano, Kamchatka. Geology 30 (12), 1059-1062.

Francis, P. N., Cooke, M. C., Saunders, R. W., 2012. Retrieval of physical properties of volcanic ash using Meteosat: A case study from the 2010 Eyjafjallajökull eruption. Journal of Geophysical Research 117 (D00U09). URL http://dx.doi.org/10.1029/2011JD016788

Gibson, J., 1950. The Perception of the Visual World. Oxford, England: Houghton Mifflin. (1950). xii 242 pp.

Harris, A., Delle Donne, D., Dehn, J., Ripepe, M., Worden, A., 2013. Volcanic plume and bomb field masses from thermal infrared camera imagery. Earth and Planetary Science Letters 365, 77-85.

Harris, A., Ripepe, M., 2007a. Synergy of multiple geophysical approaches to unravel explosive eruption conduit and source dynamics-A case study from Stromboli. Chemie der Erde-Geochemistry 67 (1), 1-35.

Harris, A., Ripepe, M., 2007b. Temperature and dynamics of degassing at Stromboli. Journal of Geophysical Research: Solid Earth 112 (B3). 
Harris, A. J., Dehn, J., Calvari, S., 2007. Lava effusion rate definition and measurement: a review. Bulletin of Volcanology 70 (1), 1-22.

Henney, L., Rodríguez, L., Watson, I., 2012. A comparison of $\mathrm{SO}_{2}$ retrieval techniques using mini-UV spectrometers and ASTER imagery at Láscar volcano, Chile. Bulletin of Volcanology 74 (2), 589-594.

Horton, K. A., Williams-Jones, G., Garbeil, H., Elias, T., Sutton, A. J., Mouginis-Mark, P., Porter, J. N., Clegg, S., 2006. Real-time measurement of volcanic $\mathrm{SO}_{2}$ emissions: validation of a new UV correlation spectrometer (FLYSPEC). Bulletin of Volcanology 68 (4), 323-327.

Izbekov, P. E., Eichelberger, J. C., Ivanov, B. V., 2004. The 1996 eruption of Karymsky volcano, Kamchatka: historical record of basaltic replenishment of an andesite reservoir. Journal of Petrology 45 (11), 2325-2345.

Jähne, B., Haussecker, H., Scharr, H., Spies, H., Schmundt, D., Schurr, U., 1998. Study of dynamical processes with tensor-based spatiotemporal image processing techniques. In: Computer Vision European Conference on Computer Vision 1998. Springer, pp. 322-336.

Jaupart, C., Vergniolle, S., 1988. Laboratory models of Hawaiian and Strombolian eruptions. Nature 331 (6151), 58-60.

Johnson, J., Lees, J., 2000. Plugs and chugs: seismic and acoustic observations of degassing explosions at Karymsky, Russia and Sangay, Ecuador. Journal of Volcanology and Geothermal Research 101 (1), 67-82.

Johnson, J. B., 2007. On the relation between infrasound, seismicity, and 
small pyroclastic explosions at Karymsky Volcano. Journal of Geophysical Research: Solid Earth 112 (B8).

Johnson, J. B., Lees, J. M., Gordeev, E. I., 1998. Degassing explosions at Karymsky volcano, Kamchatka. Geophysical Research Letters 25 (21), 3999-4002.

Kern, C., Lbcke, P., Bobrowski, N., Campion, R., Mori, T., Smekens, J.-F., Stebel, K., Tamburello, G., Burton, M., Platt, U., Prata, F., 2014. Intercomparison of $\mathrm{SO}_{2}$ camera systems for imaging volcanic gas plumes. Journal of Volcanology and Geothermal Research (0), - . URL http://www.sciencedirect.com/science/article/pii/S0377027314002662

Lautze, N. C., Houghton, B. F., 2005. Physical mingling of magma and complex eruption dynamics in the shallow conduit at Stromboli volcano, Italy. Geology 33 (5), 425-428.

Liu, H., Hong, T.-H., Herman, M., Chellappa, R., 1997. A general motion model and spatio-temporal filters for computing optical flow. International Journal of Computer Vision 22 (2), 141-172.

Liu, Y., Arnott, W. P., Hallett, J., 1999. Particle size distribution retrieval from multispectral optical depth: Influences of particle nonsphericity and refractive index. Journal of Geophysical Research: Atmospheres 104 (D24), 31753-31762.

Lopez, T., Fee, D., Prata, F., Dehn, J., 2013. Characterization and interpretation of volcanic activity at Karymsky Volcano, Kamchatka, Russia, 
using observations of infrasound, volcanic emissions, and thermal imagery. Geochemistry, Geophysics, Geosystems 14 (12), 5106-5127.

Lucas, B. D., Kanade, T., et al., 1981. An iterative image registration technique with an application to stereo vision. In: International Joint Conference on Artificial Intelligence. Vol. 81. pp. 674-679.

Marchetti, E., Ripepe, M., Harris, A., Delle Donne, D., 2009. Tracing the differences between Vulcanian and Strombolian explosions using infrasonic and thermal radiation energy. Earth and Planetary Science Letters 279 (3), $273-281$.

Mather, T., Tsanev, V., Pyle, D., McGonigle, A., Oppenheimer, C., Allen, A., 2004. Characterization and evolution of tropospheric plumes from Lascar and Villarrica volcanoes, Chile. Journal of Geophysical Research: Atmospheres 109 (D21).

Matthews, S. J., Gardeweg, M. C., Sparks, R. S. J., 1997. The 1984 to 1996 cyclic activity of Lascar Volcano, northern Chile: cycles of dome growth, dome subsidence, degassing and explosive eruptions. Bulletin of Volcanology 59 (1), 72-82.

Mori, T., Burton, M., 2009. Quantification of the gas mass emitted during single explosions on stromboli with the $\mathrm{SO}_{2}$ imaging camera. Journal of Volcanology and Geothermal Research 188 (4), 395-400.

Oppenheimer, C., Yirgu, G., 2002. Thermal imaging of an active lava lake: Erta'Ale volcano, Ethiopia. International Journal of Remote Sensing $23(22), 4777-4782$. 
Ozerov, A., Ispolatov, I., Lees, J., 2003. Modeling strombolian eruptions of Karymsky volcano, Kamchatka, Russia. Journal of Volcanology and Geothermal Research 122 (3), 265-280.

Patrick, M., 2007. The gas content and buoyancy of Strombolian ash plumes. Journal of Volcanology and Geothermal Research 166 (1), 1-6.

Patrick, M. R., Harris, A. J., Ripepe, M., Dehn, J., Rothery, D. A., Calvari, S., 2007. Strombolian explosive styles and source conditions: insights from thermal (FLIR) video. Bulletin of Volcanology 69 (7), 769-784.

Prata, A., 1989. Infrared radiative transfer calculations for volcanic ash clouds. Geophysical Research Letters 16 (11), 1293-1296.

Prata, A., Bernardo, C., 2009. Retrieval of volcanic ash particle size, mass and optical depth from a ground-based thermal infrared camera. Journal of Volcanology and Geothermal Research 186 (1), 91-107.

Prata, A., Bernardo, C., 2014. Retrieval of sulphur dioxide from a groundbased thermal infrared imaging camera. Atmospheric Measurements and Techniques Discussions 7, 1153-1211.

Prata, A., Grant, I., 2001. Retrieval of microphysical and morphological properties of volcanic ash plumes from satellite data: Application to Mt Ruapehu, New Zealand. Quarterly Journal of the Royal Meteorological Society 127 (576), 2153-2179.

URL http://dx.doi.org/10.1002/qj.49712757615

Realmuto, V., Sutton, A., Elias, T., 1997. Multispectral thermal infrared mapping of sulfur dioxide plumes: A case study from the East Rift Zone 
of Kilauea Volcano, Hawai'i. Journal of Geophysical Research: Solid Earth 102 (B7), 15057-15072.

Realmuto, V. J., Abrams, M. J., Buongiorno, M. F., Pieri, D. C., 1994. The use of multispectral thermal infrared image data to estimate the sulfur dioxide flux from volcanoes: a case study from Mount Etna, Sicily, July 29, 1986. Journal of Geophysical Research: Solid Earth 99 (B1), 481-488.

Ripepe, M., Donne, D. D., Harris, A., Marchetti, E., Ulivieri, G., 2008. Dynamics of Strombolian activity. Geophysical Monograph Series 182, 39 48.

Ripepe, M., Harris, A. J., Carniel, R., 2002. Thermal, seismic and infrasonic evidences of variable degassing rates at Stromboli volcano. Journal of Volcanology and Geothermal Research 118 (3), 285-297.

Ripepe, M., Harris, A. J., Marchetti, E., 2005a. Coupled thermal oscillations in explosive activity at different craters of Stromboli volcano. Geophysical Research Letters 32 (17).

Ripepe, M., Marchetti, E., Ulivieri, G., Harris, A., Dehn, J., Burton, M., Caltabiano, T., Salerno, G., 2005b. Effusive to explosive transition during the 2003 eruption of Stromboli volcano. Geology 33 (5), 341-344.

Ripepe, M., Rossi, M., Saccorotti, G., 1993. Image processing of explosive activity at Stromboli. Journal of Volcanology and Geothermal Research $54(3), 335-351$.

Rose, W., Durant, A., 2009. Fine ash content of explosive eruptions. Journal of Volcanology and Geothermal Research 186 (1-2), 32-39. 
Rosi, M., Bertagnini, A., Landi, P., 2000. Onset of the persistent activity at Stromboli volcano (Italy). Bulletin of Volcanology 62 (4-5), 294-300.

Stoiber, R., Malinconico, L., Williams, S., 1983. Use of the correlation spectrometer at volcanoes. Forecasting Volcanic Events 1, 425-444.

Tassi, F., Aguilera, F., Vaselli, O., Medina, E., Tedesco, D., Huertas, A. D., Poreda, R., Kojima, S., 2009. The magmatic-and hydrothermal-dominated fumarolic system at the Active Crater of Lascar volcano, northern Chile. Bulletin of Volcanology 71 (2), 171-183.

Wen, S., Rose, W. I., 1994. Retrieval of sizes and total masses of particles in volcanic clouds using AVHRR bands 4 and 5. Journal of Geophysical Research 99 (D3), 5421-5431.

Wessels, R. L., Vaughan, R. G., Patrick, M. R., Coombs, M. L., 2013. Highresolution satellite and airborne thermal infrared imaging of precursory unrest and 2009 eruption at Redoubt Volcano, Alaska. Journal of Volcanology and Geothermal Research 259, 248-269.

Wohletz, K. H., 1983. Mechanisms of hydrovolcanic pyroclast formation: grain-size, scanning electron microscopy, and experimental studies. Journal of Volcanology and Geothermal Research 17 (1), 31-63. 
Table 1: nicAIR technical specifications.

\begin{tabular}{|c|c|}
\hline Total field-of-view & $32^{\circ} \times 24^{\circ}$ \\
\hline Optics & $35 \mathrm{~mm} \mathrm{~F} 1.4$ Ge lens \\
\hline Image size & $640 \times 512$ pixels \\
\hline Number of filters & up to 4 \\
\hline Channel $1\left(\mathrm{SO}_{2}\right)$ & $8.6 \mu \mathrm{m}$ \\
\hline Channel 2 (Plume temperature) & $10.0 \mu \mathrm{m}$ \\
\hline Channel 3 (Ash) & $11.0 \mu \mathrm{m}$ \\
\hline Channel 4 (Ash) & $12.0 \mu \mathrm{m}$ or $8-13 \mu \mathrm{m}$ (broadband) \\
\hline Sampling rate (max for single channel;) & $\sim 1 \mathrm{~Hz}$ \\
\hline Detector & Uncooled microbolometer \\
\hline NE $\Delta \mathrm{T}$ Filter 1 & $500 \mathrm{mK} @ 250 \mathrm{~K}$ \\
\hline NE $\Delta \mathrm{T}$ Filter 2 & $200 \mathrm{mK} @ 250 \mathrm{~K}$ \\
\hline NE $\Delta \mathrm{T}$ Filter 3 & $200 \mathrm{mK} @ 250 \mathrm{~K}$ \\
\hline NE $\Delta \mathrm{T}$ Filter 4 & $200 \mathrm{mK} @ 250 \mathrm{~K}$ \\
\hline NEAT Broadband & $50 \mathrm{mK} @ 250 \mathrm{~K}$ \\
\hline Requirements & $12 \mathrm{~V}, 3 \mathrm{~A}, 40 \mathrm{~W}$ peak \\
\hline Accuracy $\left(\mathrm{SO}_{2}\right)$ & $\pm 0.2 \mathrm{~g} \mathrm{~m}^{-2}$ (or $\pm 20 \%$, whichever is higher) \\
\hline Accuracy (silicate particles) ${ }^{1}$ & $\pm 0.5 \mathrm{~g} \mathrm{~m}^{-2}$ (or $\pm 40-60 \%$, whichever is higher) \\
\hline Detection range & $\sim 10 \mathrm{~km}$ \\
\hline Operating temperature range & $-10{ }^{\circ} \mathrm{C}$ to $+50{ }^{\circ} \mathrm{C}$ \\
\hline Weight & $8 \mathrm{~kg}$ \\
\hline Dimensions & $300 \mathrm{~mm}$ x $160 \mathrm{~mm}$ x $160 \mathrm{~mm}(\mathrm{LxWxH})$ \\
\hline
\end{tabular}

${ }^{1}$ For particles in the range $1-16 \mu \mathrm{m}$ radius. 


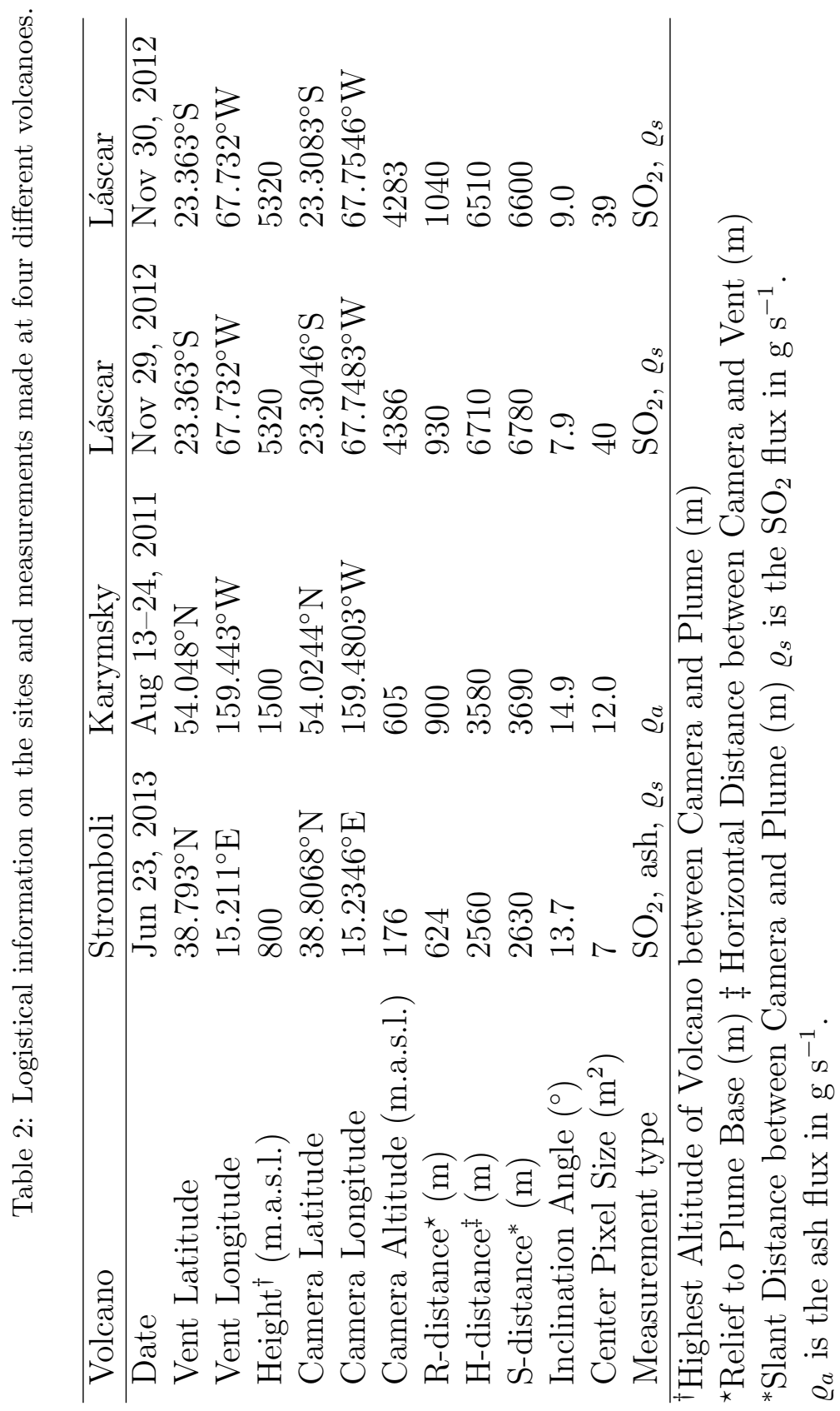




\section{FIGURES}

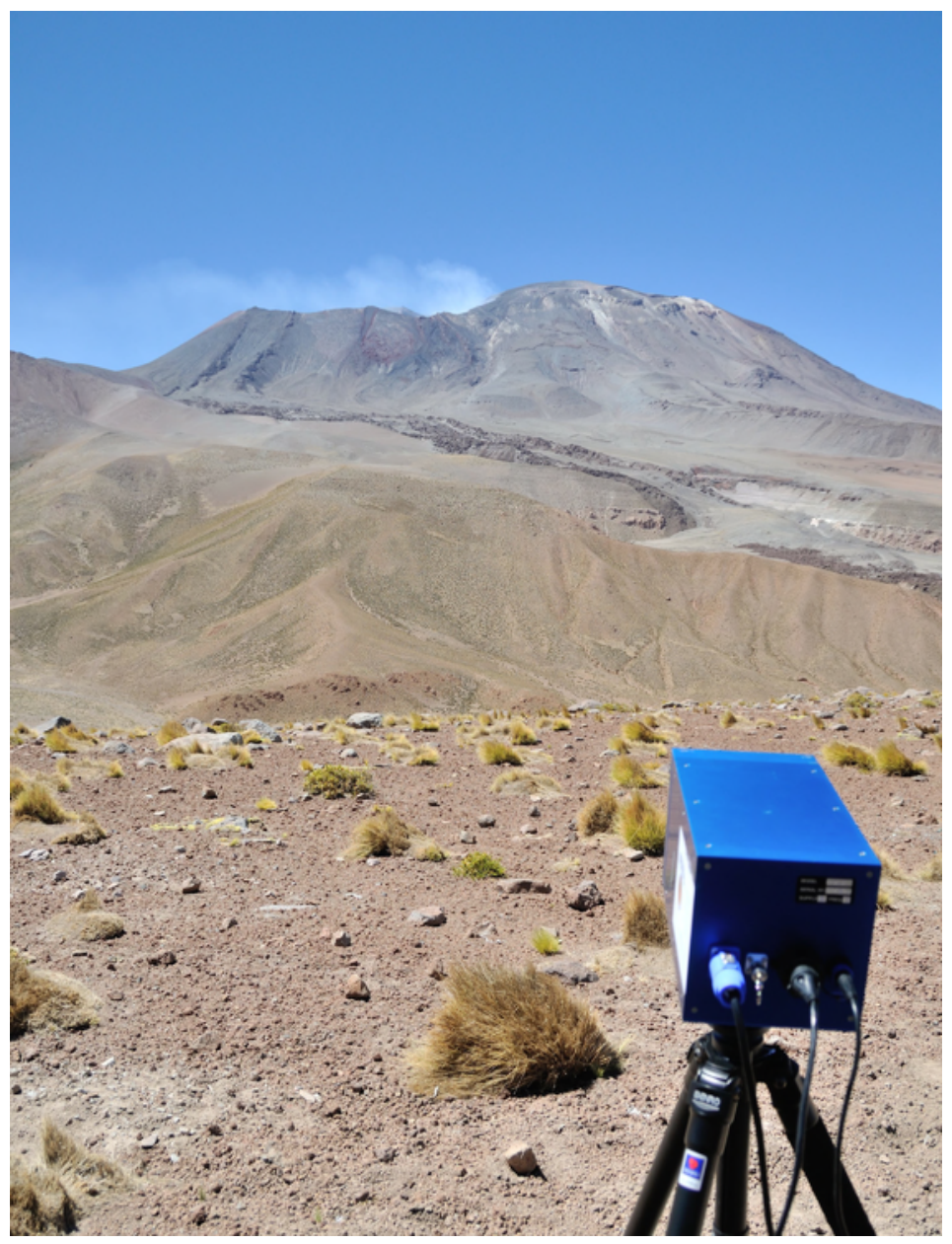

Figure 1: Photograph of the nicAIR camera viewing the $\mathrm{SO}_{2}$ plume from Láscar. The character of the plume, low altitude and close to the volcano was typical of its behavior during the measurements on 29-30 November 2012. 


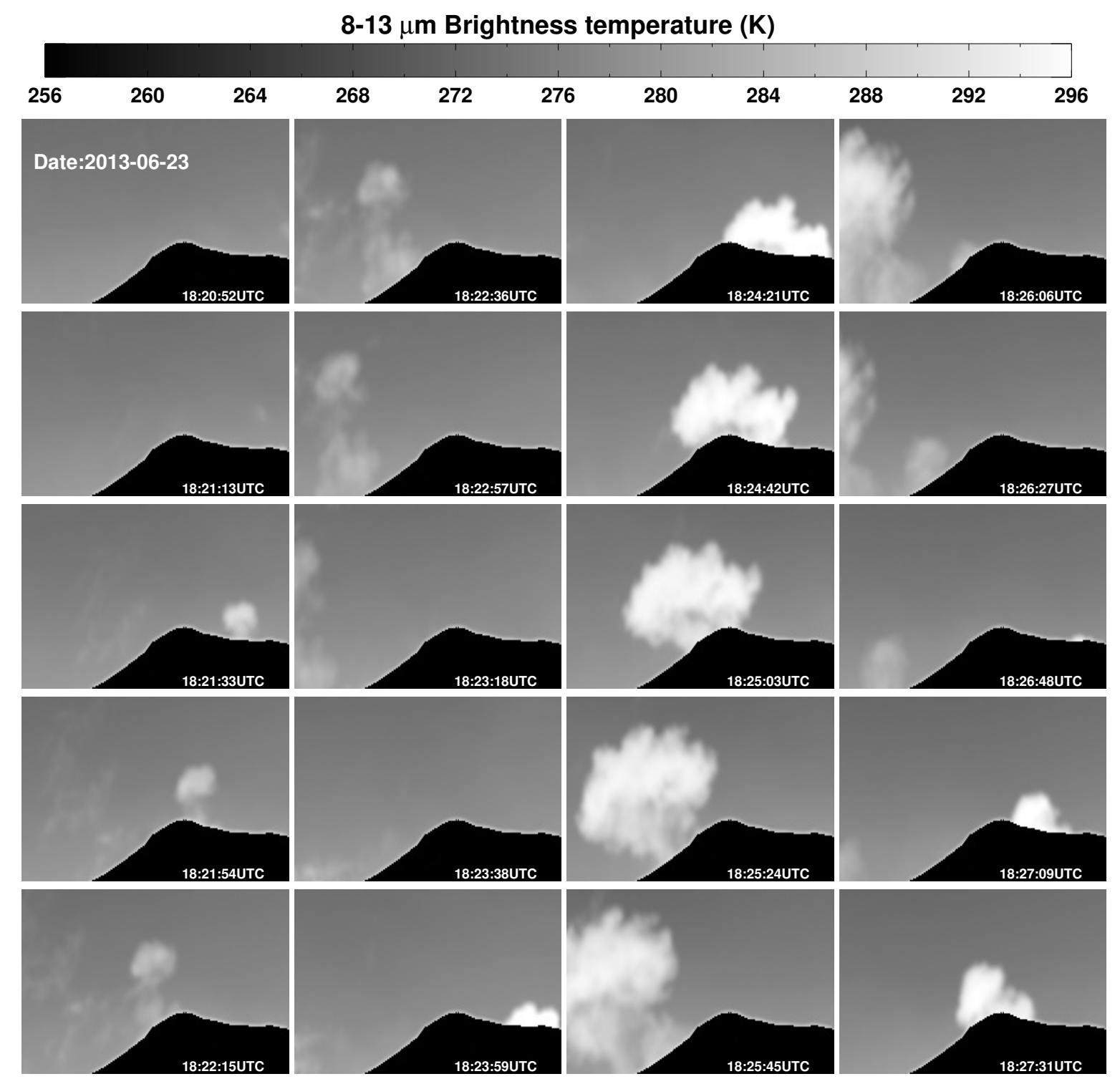

Figure 2: Broadband $(8-13 \mu \mathrm{m})$ infrared images of Strombolian ash explosions. Each image is separated in time by $\sim 20 \mathrm{~s}$; a time stamp is shown at the bottom right of each image frame. Images are shown sequentially from top-left (earliest) to bottom right (latest). Data acquired on 23 June 2012 during the Stromboli Plume Workshop. 


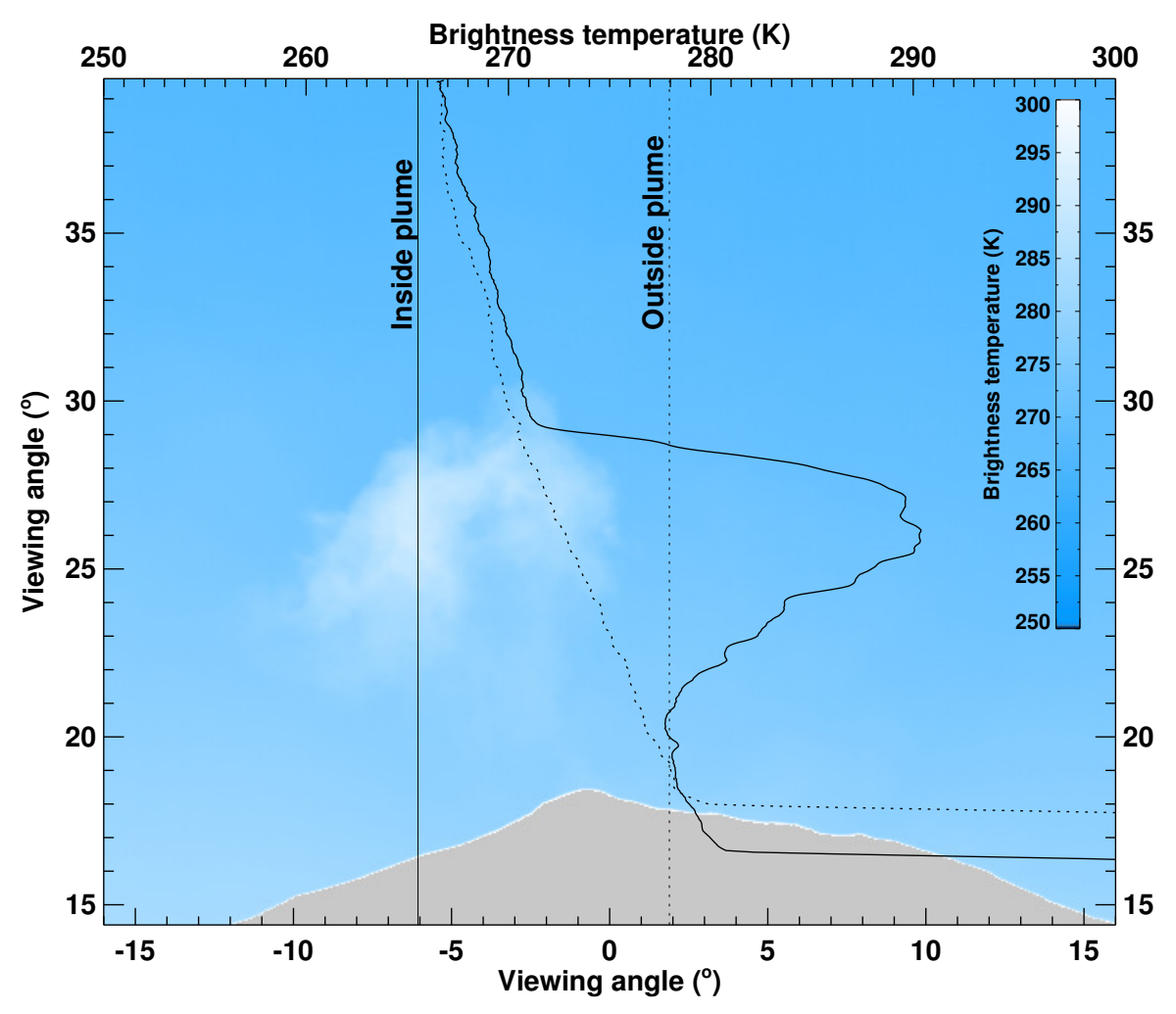

Figure 3: Broadband $(8-13 \mu \mathrm{m})$ infrared image showing an 'ashy' Strombolian plume. Vertical temperature profiles inside the plume (black solid line) and outside the plume (dashed line) illustrate the plume and environmental vertical temperature variation. The plume temperature is taken to be the maximum of the profile and is corrected for a constant lapse rate determined from the profile outside the plume. Horizontal temperature variations in the plume are assumed to be solely due to opacity variations. 


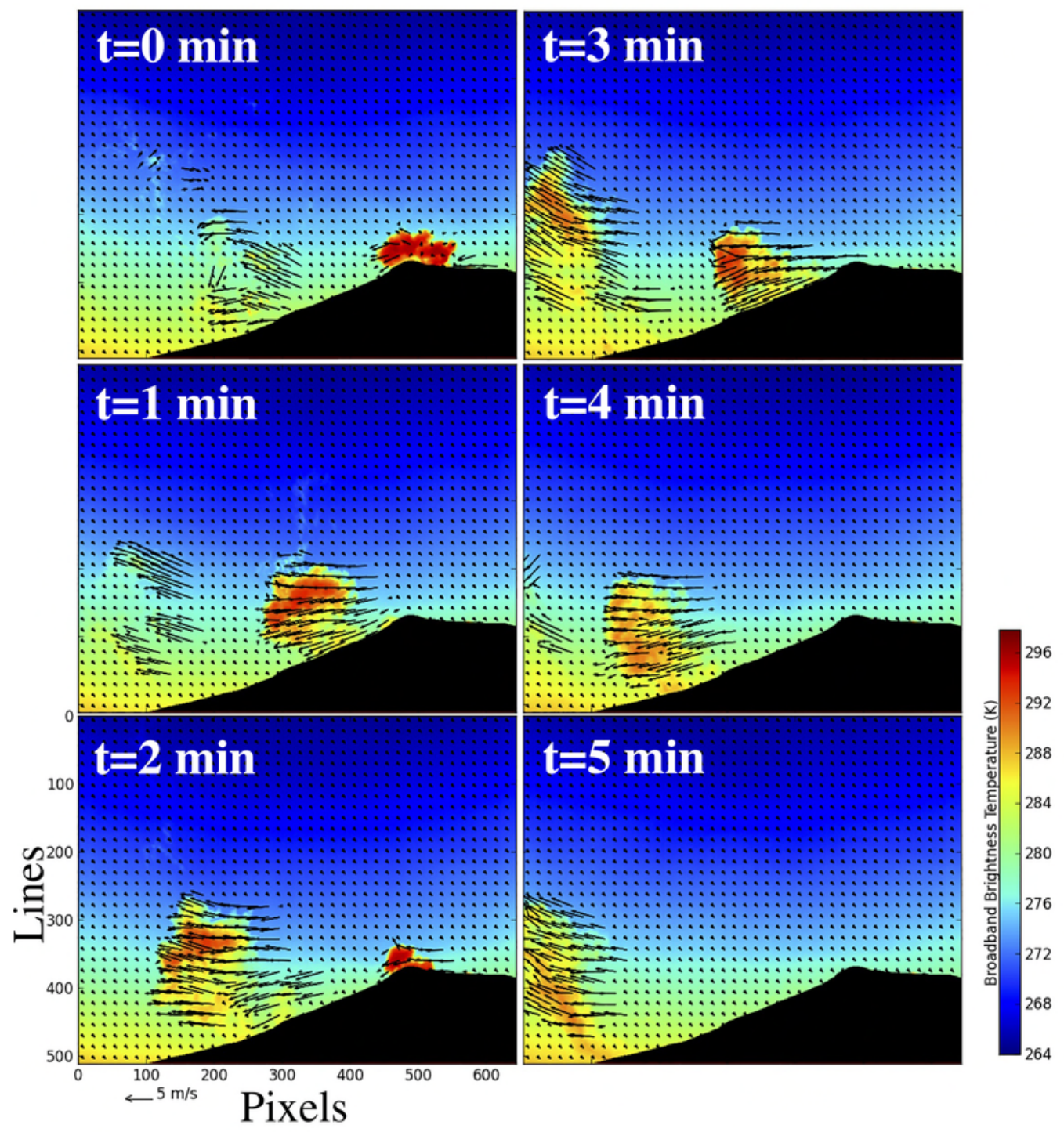

Figure 4: Motion vectors determined using broadband IR imagery at $\sim 1$ min intervals for an ash explosions at Stromboli. During the study period the ash plumes tended to reach neutral buoyancy within $\sim 2-5$ minutes and then migrated towards the southeast in the light winds. In this example three separate explosions can be seen. 

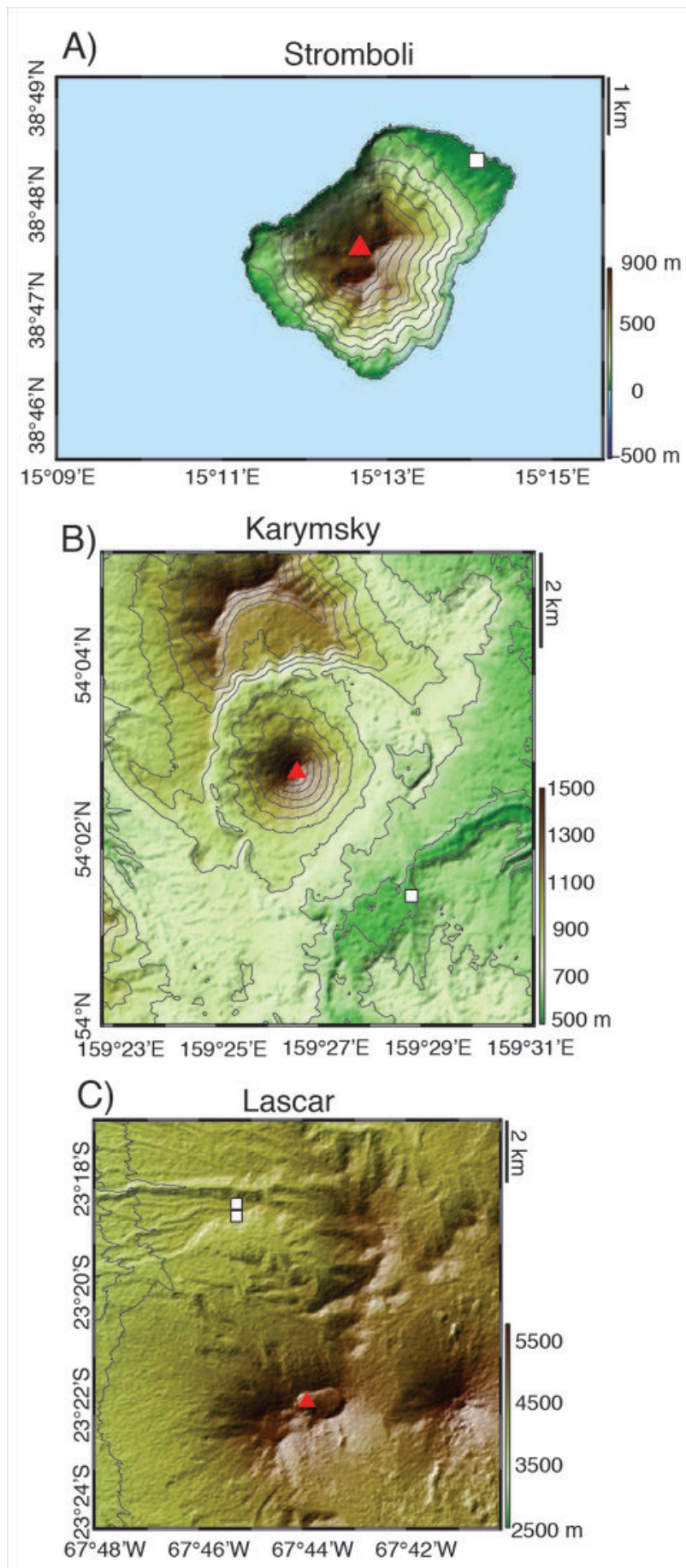

Figure 5: Topographic data for the three volcanoes studied: A) Stromboli (Italy), B) Karymsky (Russia), and C) Láscar (Chile). The location of the camera is indicated on each map by a white square and the location of the active vent by a red triangle. 

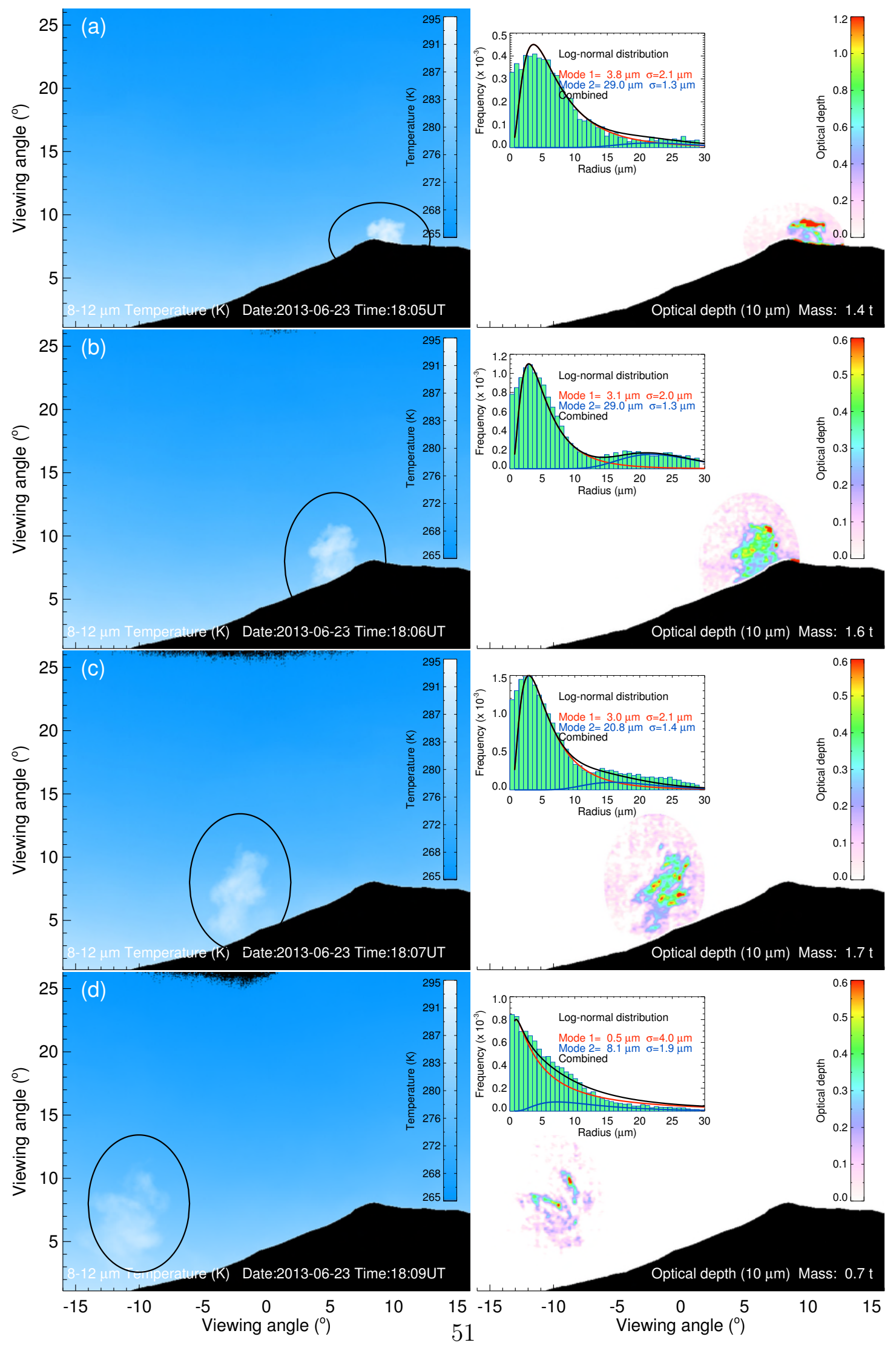

Figure 6: Four image pairs of an ash explosion at Stromboli on 23 June 2013: lefthand panels are the broadband temperature image and the right-hand panels show the optical depth retrievals for the elliptical regions shown. A two parameter log-normal size distribution fit to the data is shown for each image in the inset graphic. (a) 18:05 UT, (b) 18:06 UT, (c) 18:07 UT, and (d) 18:09 UT. 


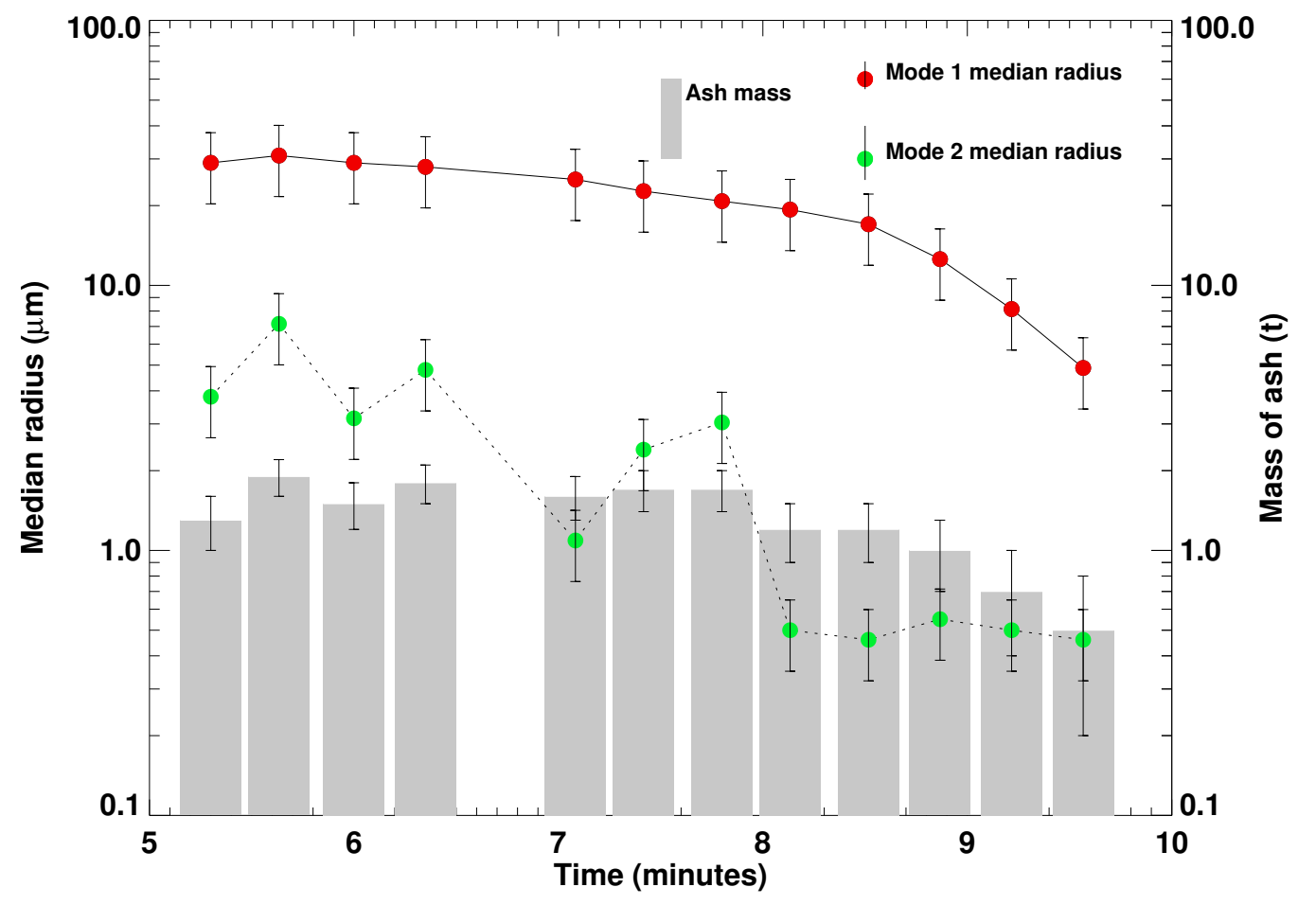

Figure 7: Temporal evolution of the two size modes found for the Stromboli ash eruptions. Mode 1 contains particles with particle radii $>10 \mu \mathrm{m}$. Mode 2 is a fine mode with mean particle radii $\sim<10 \mu \mathrm{m}$. Both modes decrease in size from the start to the end of the sequence. The fine ash mass determined from the data (grey colored bars) is $<2000 \mathrm{~kg}$ for this small ash explosion. The time is minutes past 18:00 UTC on 23 June 2013. 

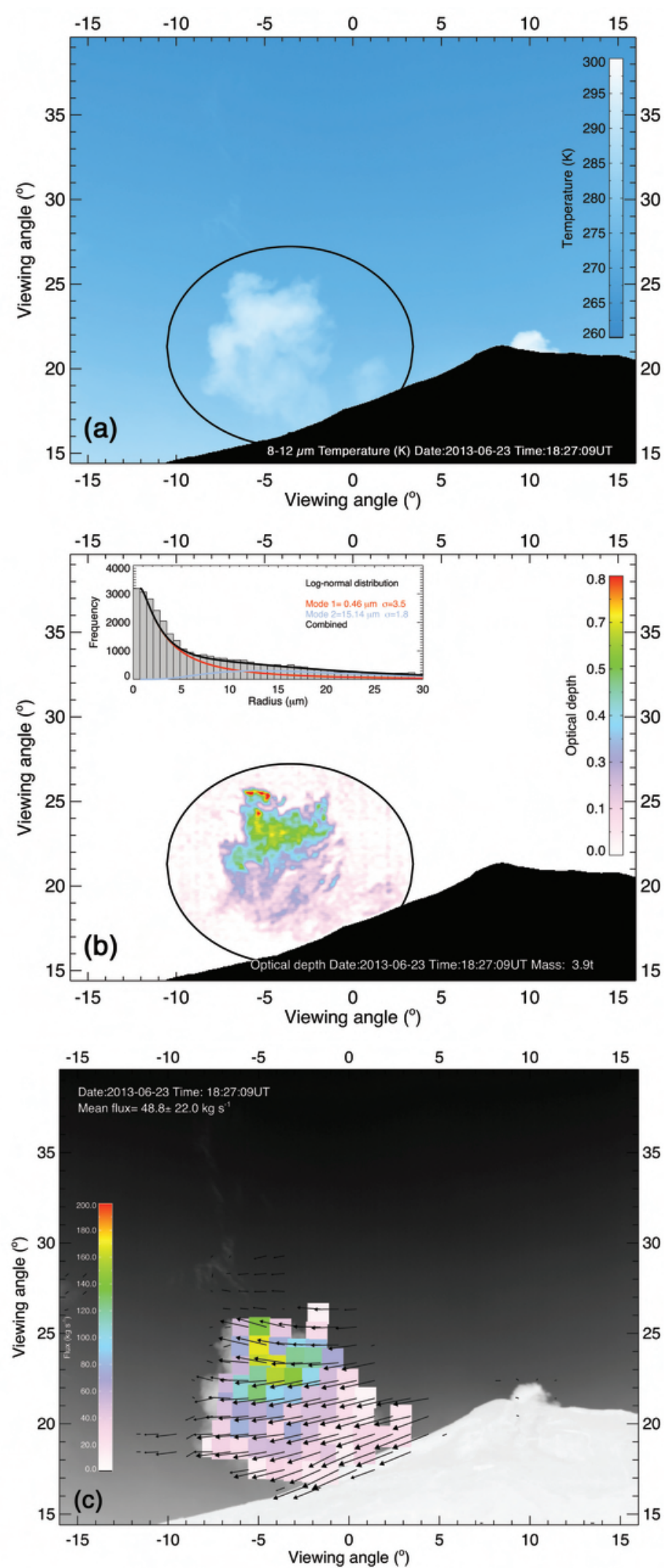

53

Figure 8: (a) Broadband image, (b) ash SCD and, (c) fine ash mass flux, derived from infrared image data for a discrete Strombolian eruption at 18:27:09 UT on 23 June 2013. 


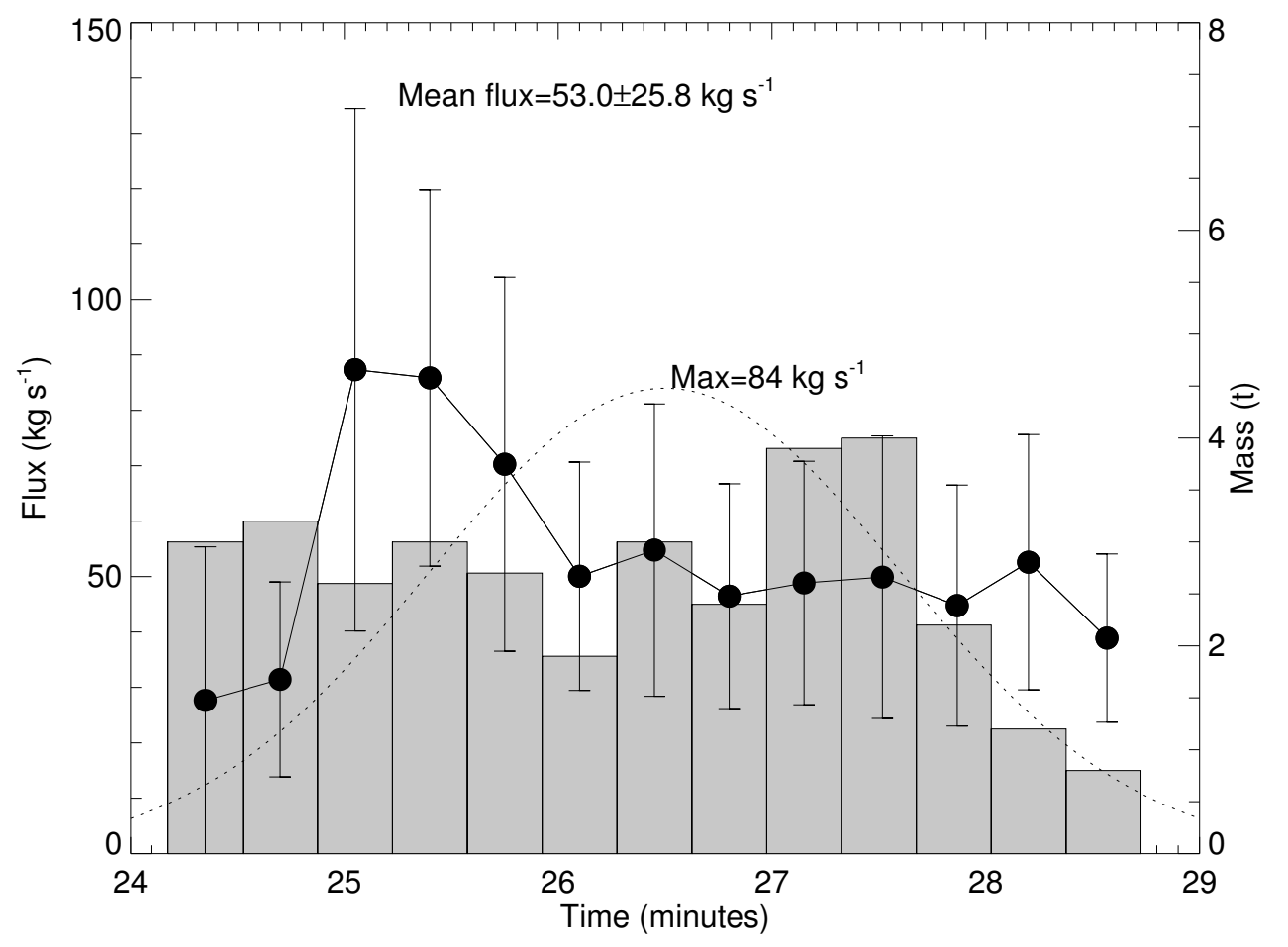

Figure 9: Temporal evolution of the fine ash mass (grey-color bars) and flux (black filled circles) for a single explosion from Stromboli over the observed lifetime from first appearance in the atmosphere until last appearance when the optical depth drops below the nicAIR detection capability. Also, shown as a dashed line is a Gaussian profile centered at 26.5 minutes with a spread of 1.1 minutes and a maximum mass flux of $84 \mathrm{~kg} \mathrm{~s}^{-1}$. The time is minutes past 18:00 UT on 23 June 2013. 


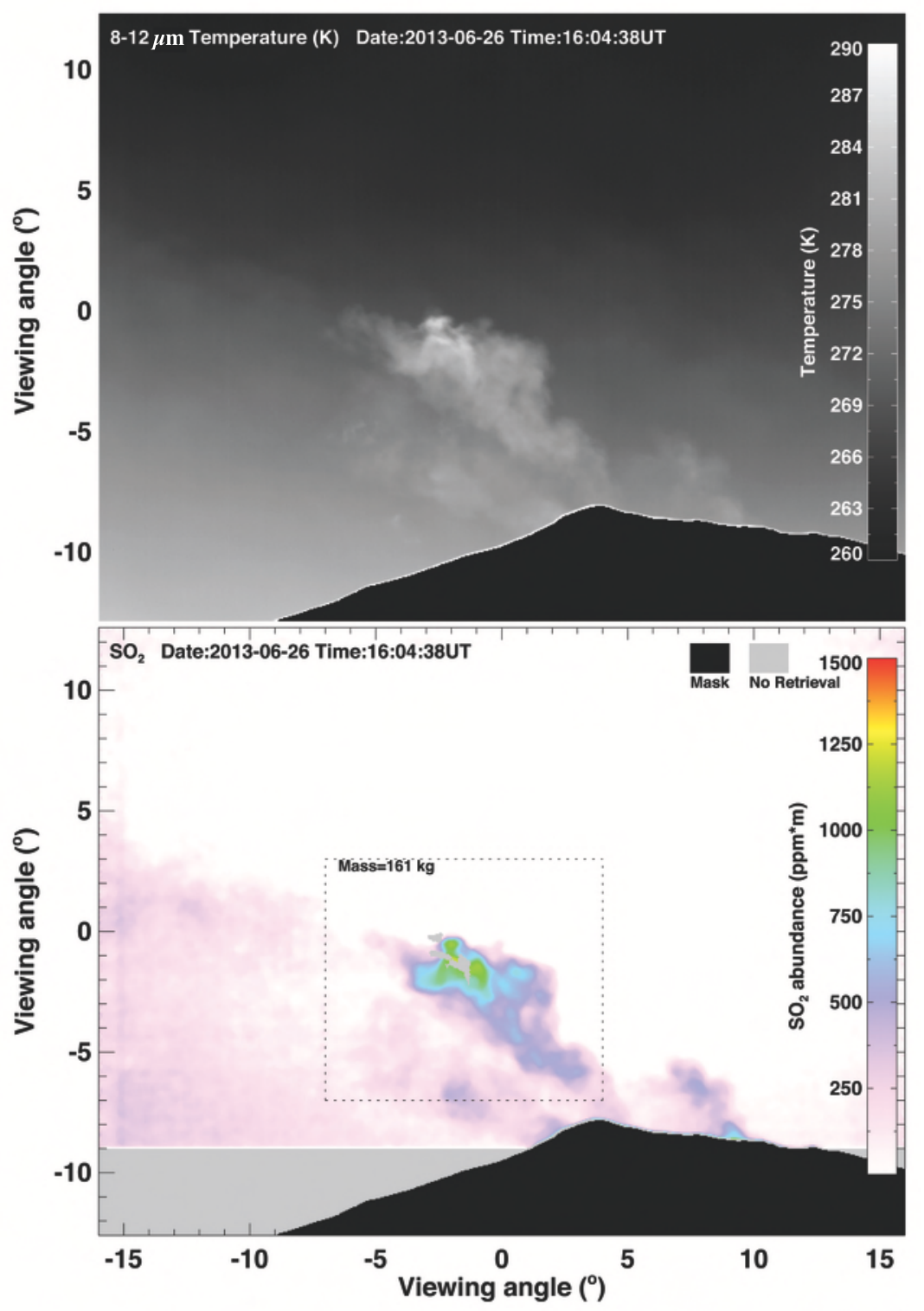

Figure 10: $\mathrm{SO}_{2}$ mass determined from the nicAIR camera at 16:04 UT on 26 June 2012, when six UV cameras were operating. See Kern et al. (2014) for results from the UV retrievals. Units are given as ppm*m for consistency with the results presented in Kern et al. (2014). 

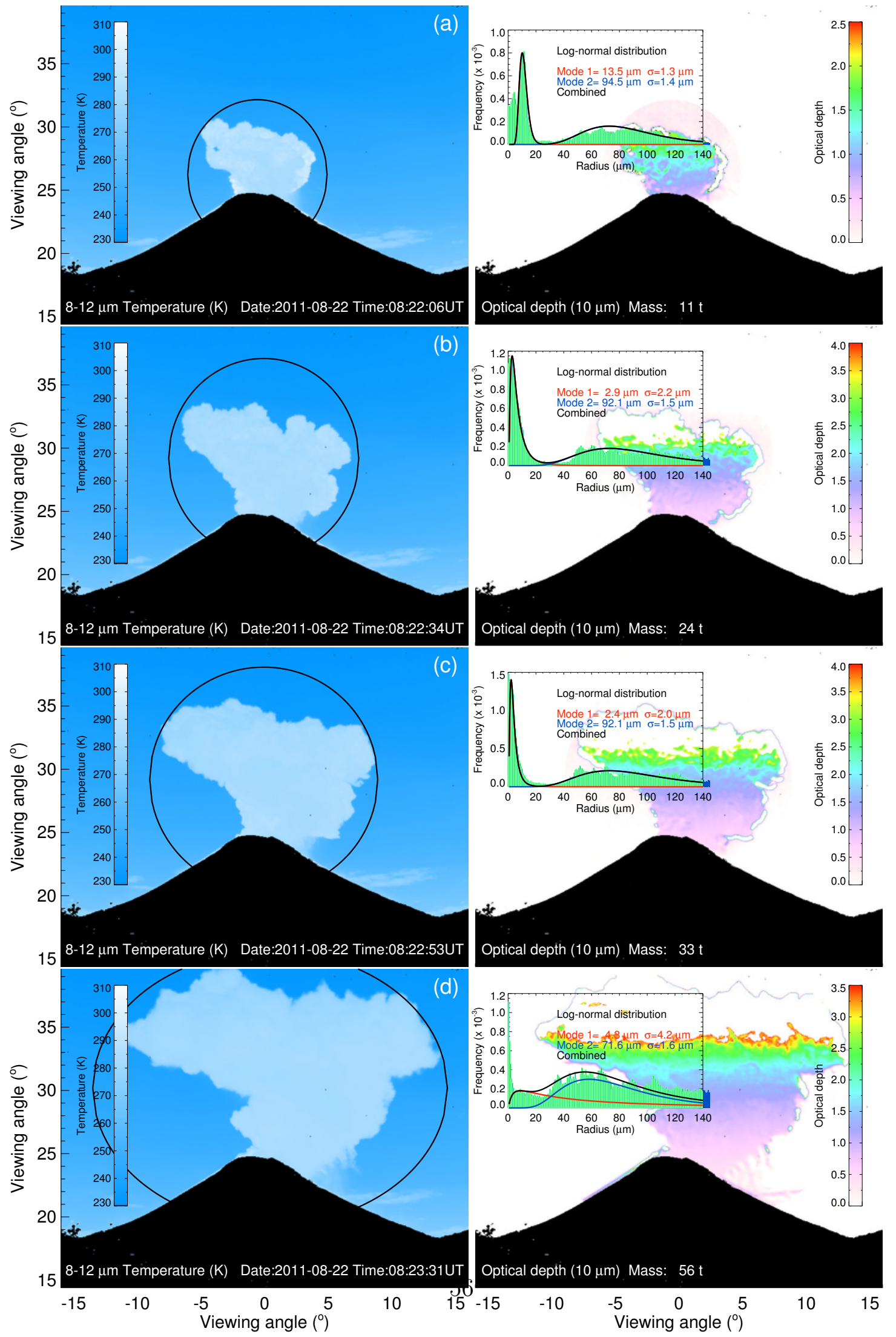

Figure 11: Sequence of four images of a large ash-rich explosion from Karymsky Volcano on 22 August 2011. The left-hand panel in each of the sequences shows the brightness temperature in the broadband channel, and the right-hand panel shows the optical depth with an inset panel showing the size distribution and a two-parameter log-normal fit. (a) 08:22:06 UT, (b) 08:22:34 UT, (c) 08:22:53 UT and (d) 08:23:31 UT. 

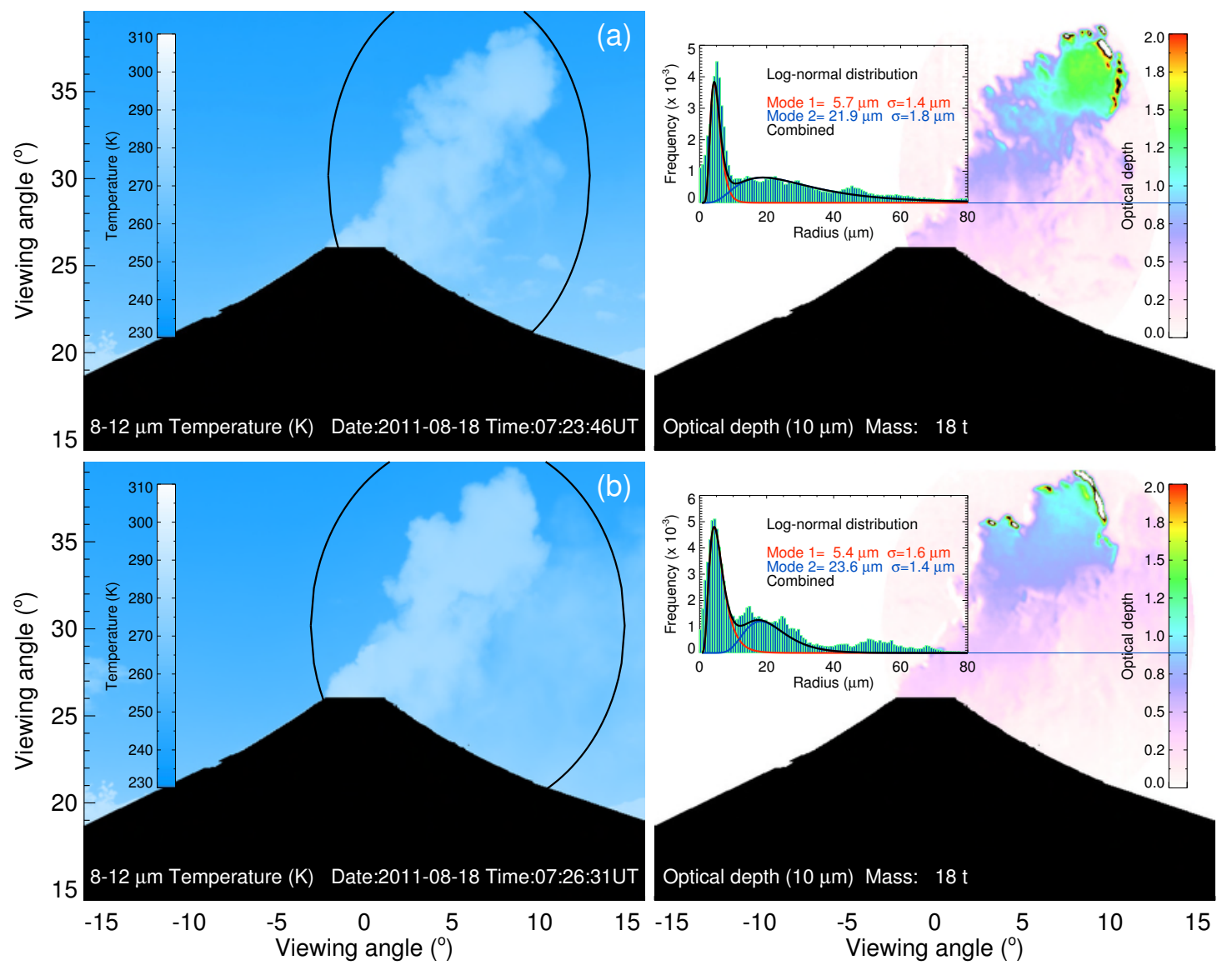

Figure 12: Two nicAIR images of a small ash explosion from Karymsky on 18 August 2011. The images show the ash plumes some time after the initial explosion. In these cases the optical depth of the column is mostly small and the total fine ash masses retrieved is more reliable. (a) Image acquired at 07:23:46 UT, and (b) image acquired at 07:26:31 UT. 


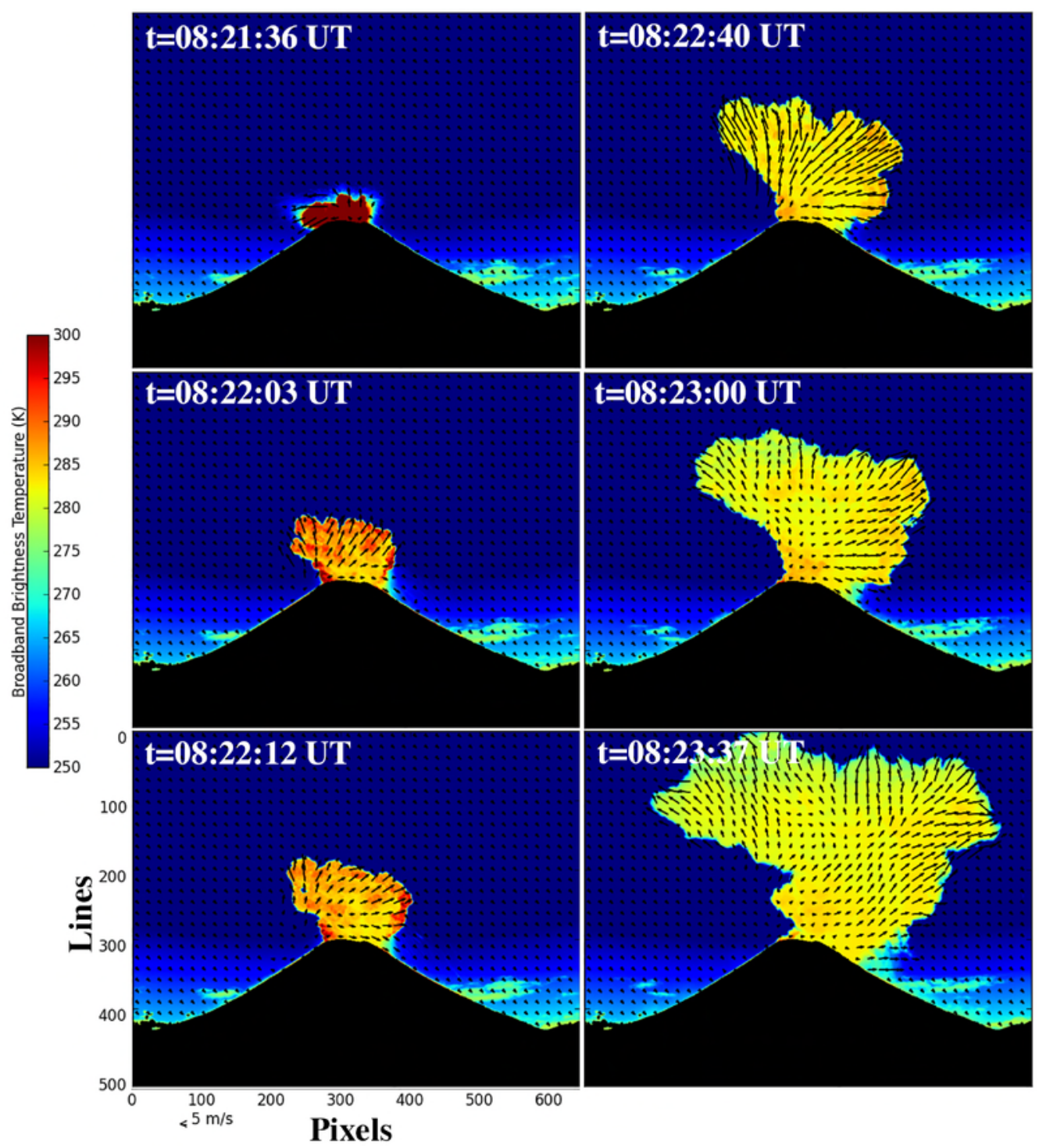

Figure 13: Eruption velocity vectors determined using the optical flow algorithm for the same Karymsky ash eruption on 22 August 2011 as Figure 11. The times of acquisition of each image are shown in each panel. 


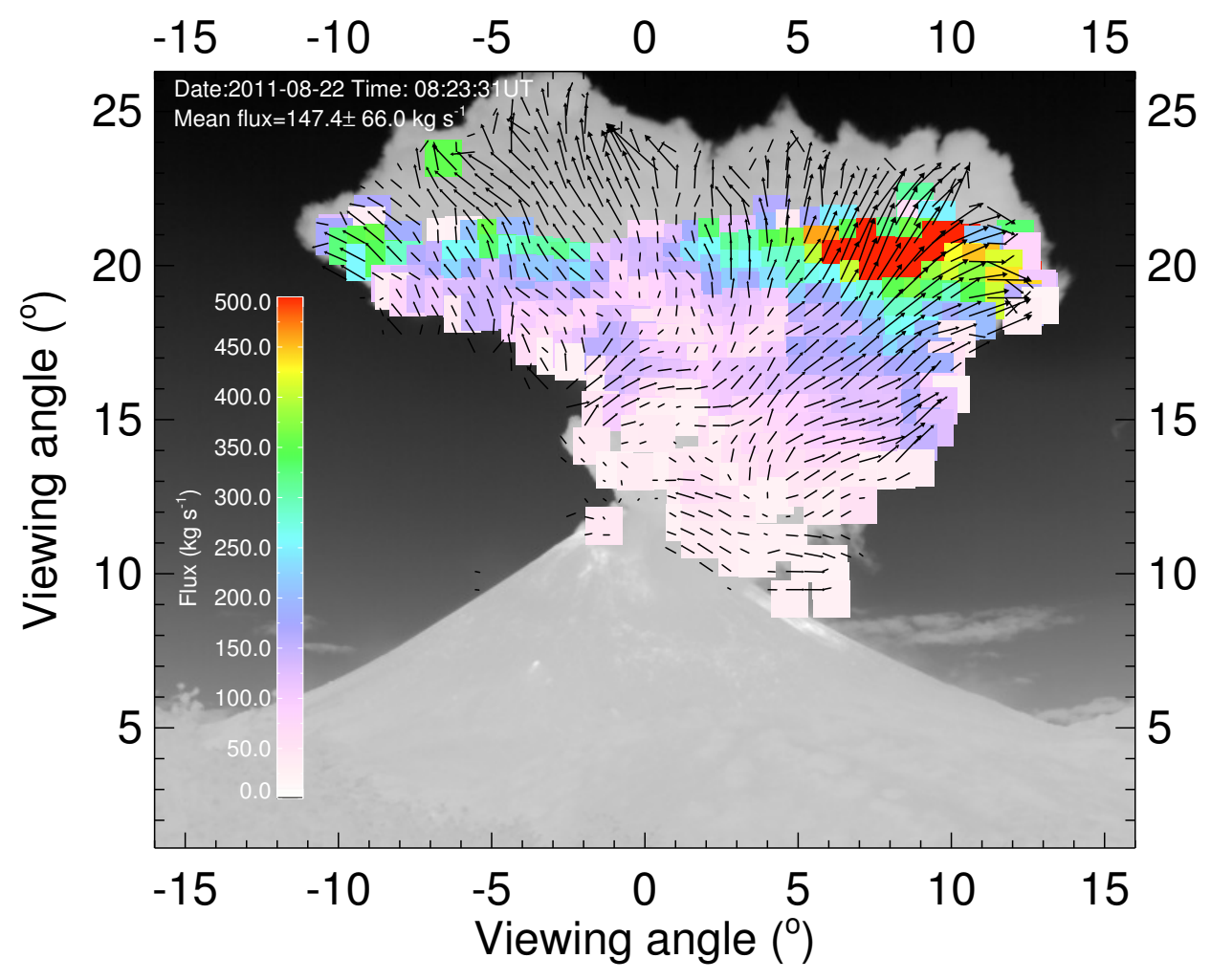

Figure 14: Fine ash mass flux determined for the large Karymsky eruption determined using the plume velocity and fine ash mass retrievals for the last image in the sequence shown in Figure 13. 

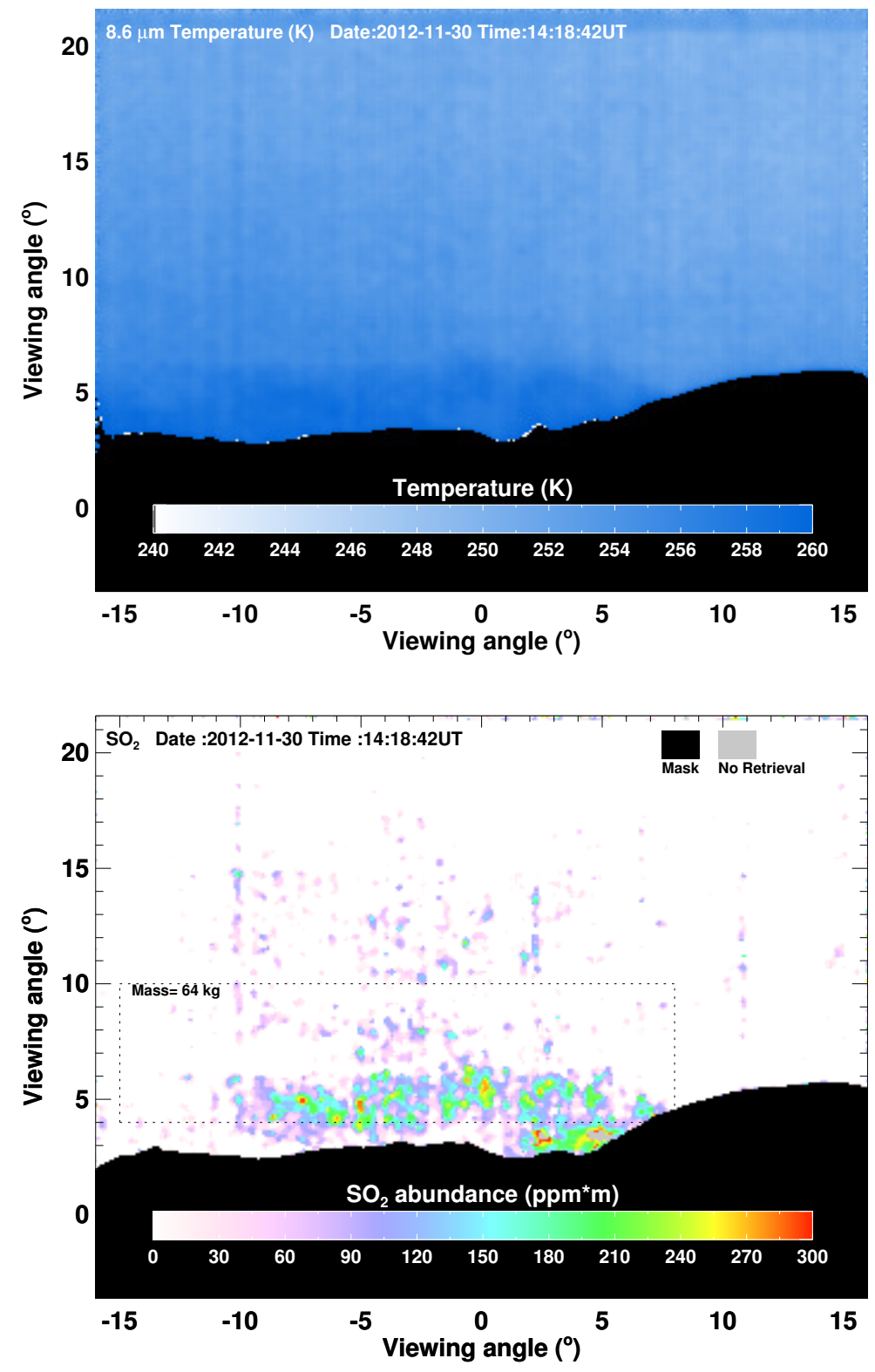

Figure 15: Top: $8.6 \mu \mathrm{m}$ image of the Láscar $\mathrm{SO}_{2}$ plume on 29 November 2012. Bottom: $\mathrm{SO}_{2}$ retrieval for a section of the image that includes the plume. The total mass of $\mathrm{SO}_{2}$ in this section is $\sim 64 \pm 20 \mathrm{~kg}$. 

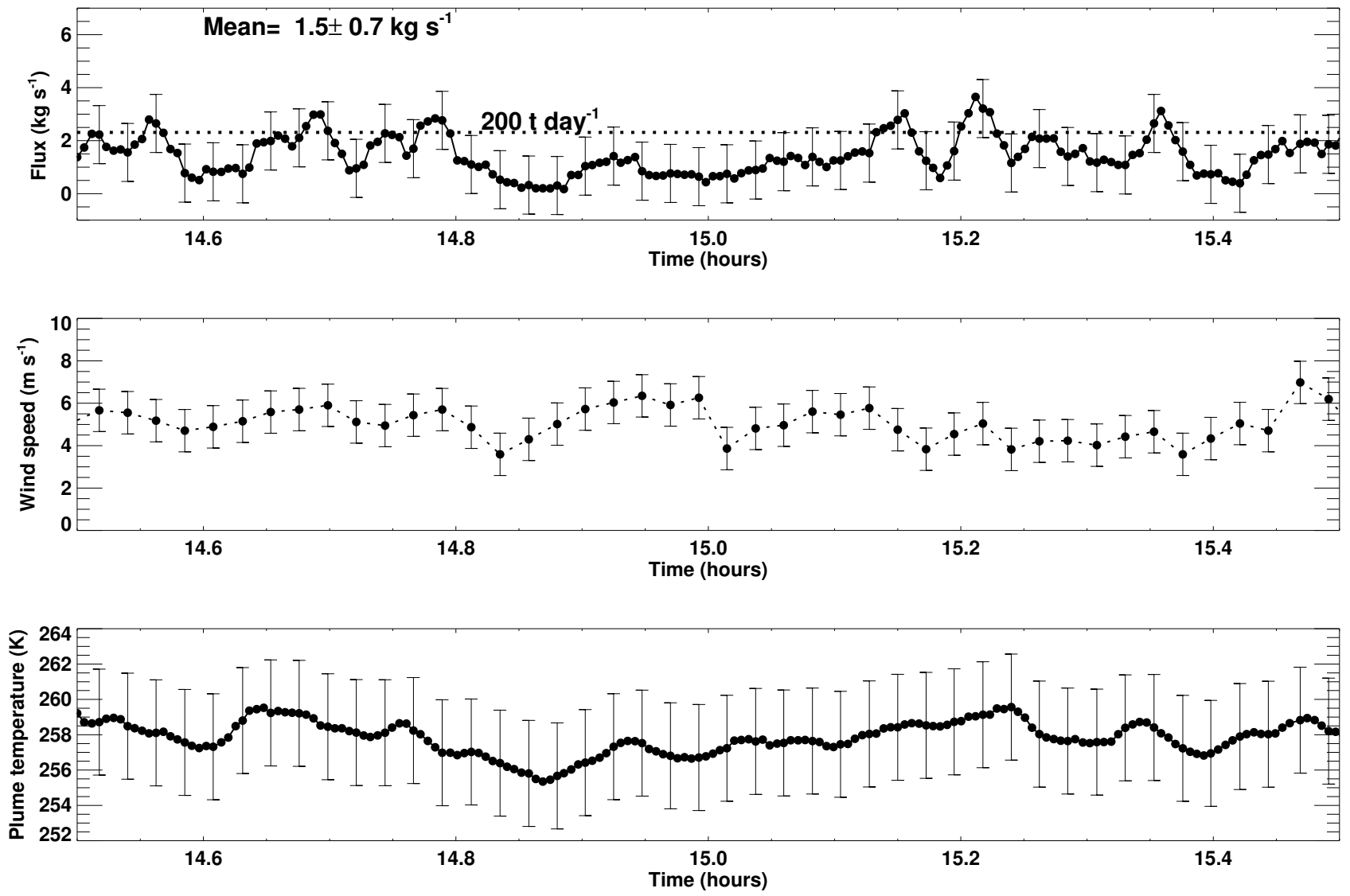

Figure 16: Time series of $\mathrm{SO}_{2}$ fluxes (top panel), wind speed $\left(\mathrm{m}^{-1}\right)$ (middle panel) and plume temperature (K) (bottom panel), for Láscar on 29 November 2011. The data have been smoothed with a filter over a $\sim 1$ min interval. The wind speeds are determined approximately every 1 minute and then smoothed to reduce noise. The mean and standard deviation of the flux were determined over $1 \mathrm{hr}$ of measurements. Error bars are shown for all of the parameters. The plume temperature error is assumed to be $\pm 3 \mathrm{~K}$ and the wind speed error is estimated at $\pm 1 \mathrm{~ms}^{-1}$, or $\sim \pm 20 \%$ of the magnitude of the wind speed. 


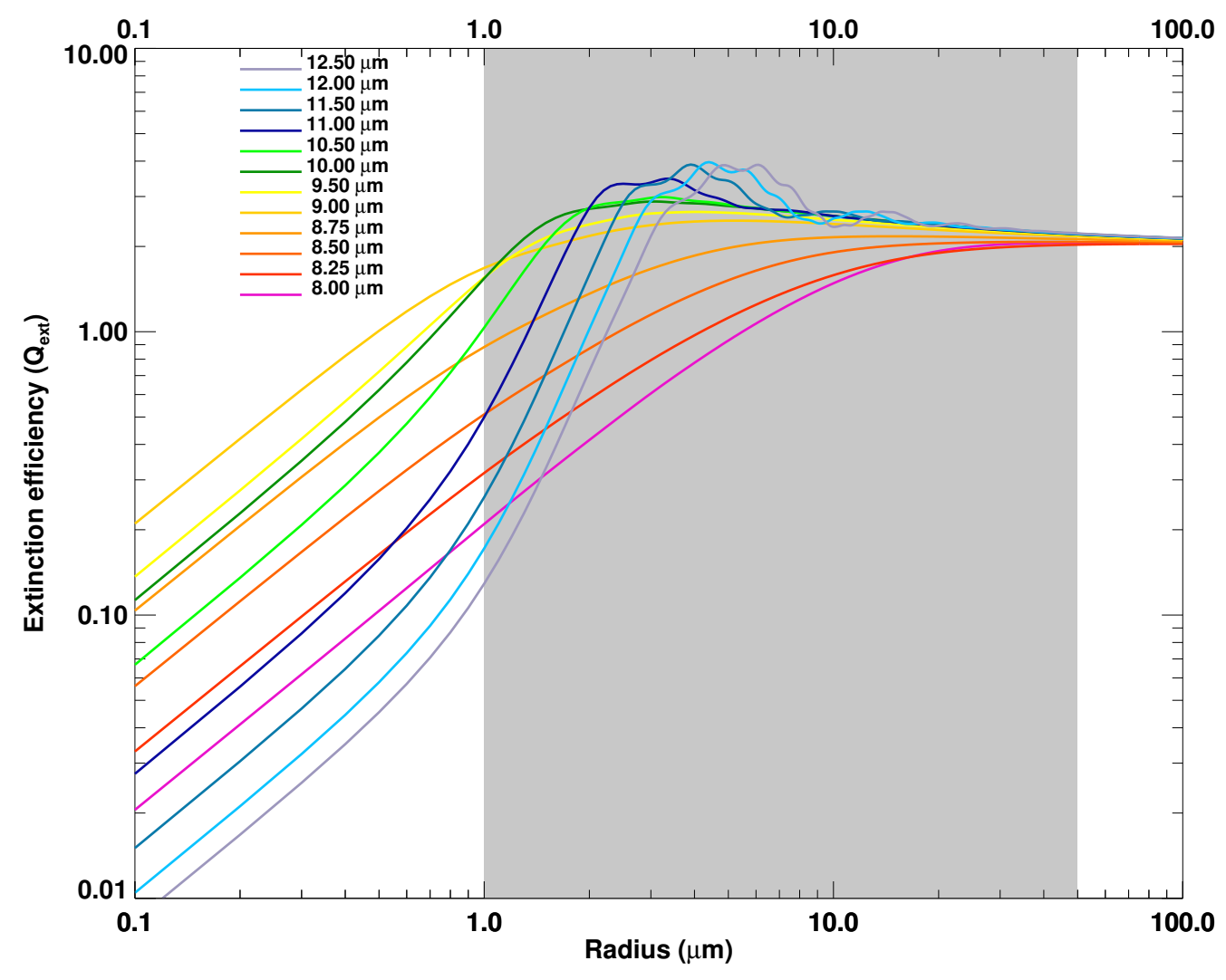

Figure 17: Extinction kernels for different monochromatic wavelengths as a function of particle size. The shaded region (grey) shows the particle size range of validity. Outside these limits the optical depth retrieval is inaccurate. 


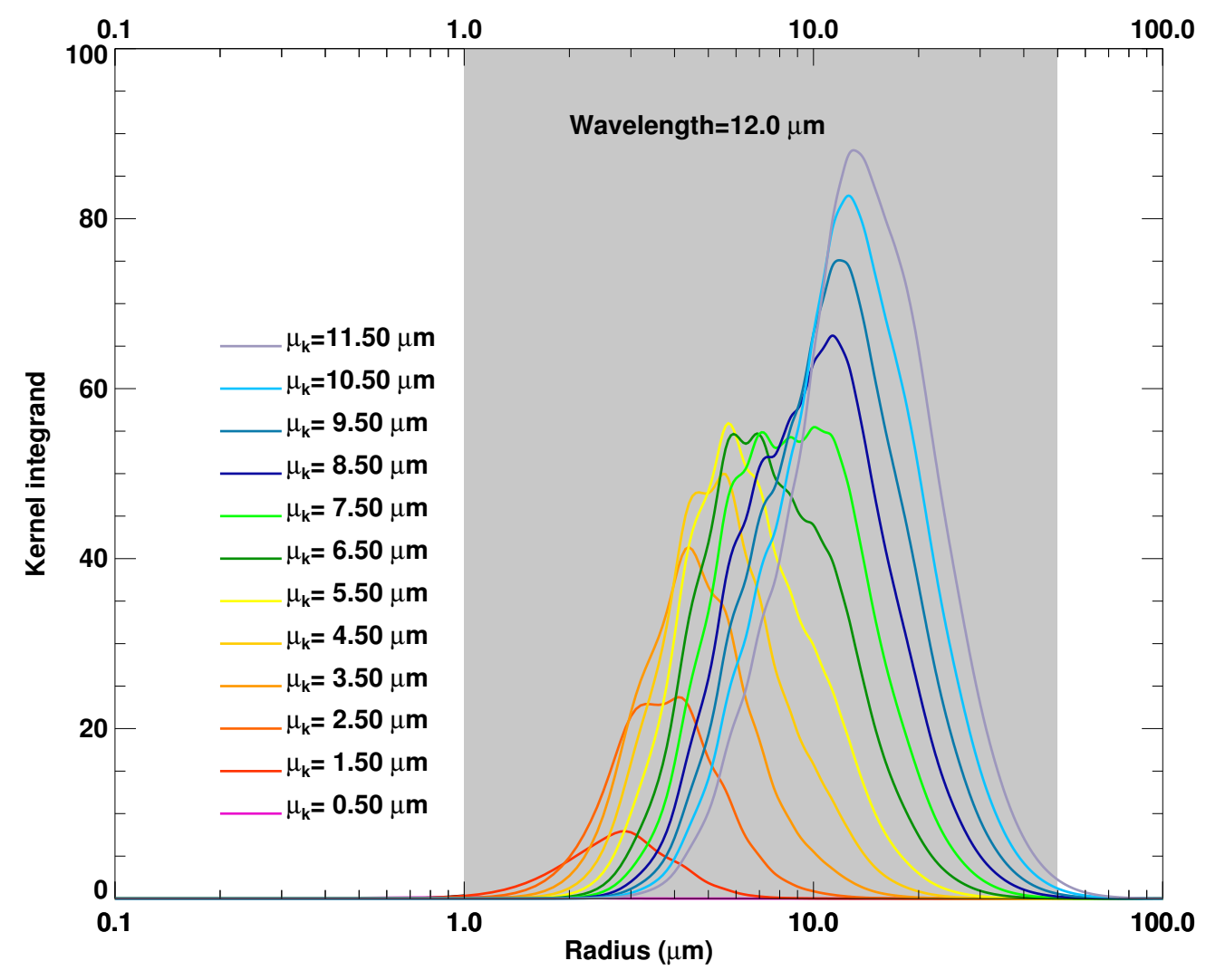

Figure 18: Variation of the product of the kernel function and size distribution (the integrand in equation A-3) as a function of particle size for several different log-normal PSDs with different means but the same standard deviation of $\sigma=1.6 \mu \mathrm{m}$, computed at $\lambda=12 \mu \mathrm{m}$. The shaded region (grey) shows the particle size range of validity. 